
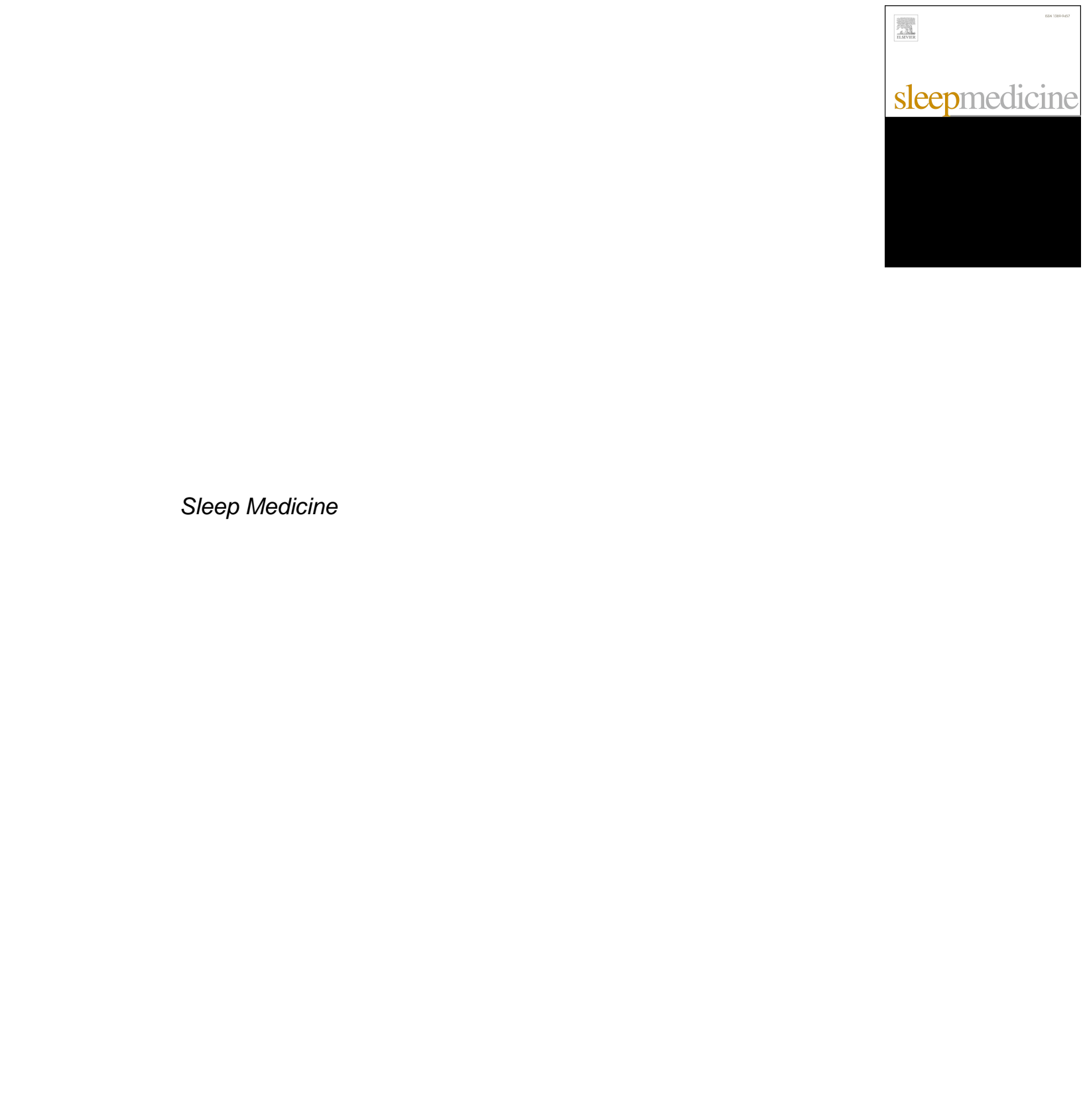


\section{Sleep Disruption and Duration are Associated with Variants in Genes Involved in Energy Homeostasis in Adults with HIV/AIDS}

Bradley E. Aouizerat, MS, $\mathrm{PhD}^{1,2}$; Eeeseung Byun, RN, $\mathrm{PhD}^{3}$; Clive R. Pullinger, $\mathrm{PhD}^{4,5}$; Caryl Gay, $\mathrm{PhD}^{6,7}$; Anners Lerdal, RN, $\mathrm{PhD}^{7,8}$; Kathryn A. Lee, RN, $\mathrm{PhD}^{6}$

${ }^{1}$ Bluestone Center for Clinical Research, New York University, NY, USA

${ }^{2}$ Department of Oral and Maxillofacial Surgery, New York University, NY, USA

${ }^{3}$ Department of Biobehavioral Nursing and Health Informatics, University of Washington, Seattle, WA

${ }^{4}$ Cardiovascular Research Institute, University of California at San Francisco, San Francisco, CA

${ }^{5}$ Department of Physiological Nursing, University of California at San Francisco, San Francisco, CA

${ }^{6}$ Department of Family Health Care Nursing, University of California at San Francisco, San Francisco, CA

${ }^{7}$ Department of Patient Safety and Research, Lovisenberg Diakonale Hospital, Oslo, Norway

${ }^{8}$ Department of Interdisciplinary Health Sciences, Institute of Health and Society, Faculty of Medicine, University of Oslo, Norway

Corresponding Author: Bradley E. Aouizerat, MS, PhD Bluestone Center for Clinical Research Department of Oral and Maxillofacial Surgery 345 E. 24th Street, Room 1024S New York, NY 10010 (212) 998-9167 (phone) (212) 995-4843 (fax) bea4@nyu.edu

Number of tables: 6

Number of figures: 2

Abstract word count: 250 (250 max)

Word count: 5,399

Number of references: 91 


\section{Abstract}

Objective: To determine whether selected genes and plasma markers involved in energy homeostasis are associated with sleep disruption or duration in adults with HIV/AIDS.

Methods: A sample of 289 adults with HIV/AIDS wore a wrist actigraph for 72 hours to estimate total sleep time (TST) and wake after sleep onset (WASO). Twenty-three single nucleotide polymorphisms (SNP) spanning 5 energy homeostasis genes (adiponectin [ADIPOQ], ghrelin $[G H R L]$, leptin $[L E P]$, peroxisome proliferator-activated receptor-alpha [PPARA], and -gamma $[$ PPARG]) were genotyped using a custom array. Plasma markers of energy homeostasis (adiponectin, ghrelin, leptin) were measured by commercial multiplex assay.

Results: After adjusting for demographic and clinical characteristics (race/ethnicity, gender, CD4 cell count, waist circumference, medications), both WASO and TST were associated with SNPs in ADIPOQ (rs182052), LEP (rs10244329, rs3828942), PPARA (rs135551, rs4253655), and PPARG (rs709151). Additional SNPs in ADIPOQ were associated with WASO (rs1501299, rs3821799, rs6773957) and TST (rs2241766). TST was also associated with SNPs in GHRL (rs26802), LEP (rs11760956), PPARA (rs135547, rs8138102, rs4253776), and PPARG (rs12490265, rs796313). Many covariate-adjusted associations involved a significant interaction with markers of HIV (viral load, years since diagnosis). Among plasma markers, higher adiponectin was associated with less WASO, higher ghrelin and glucose levels with shorter TST, and higher leptin with longer TST.

Conclusions: Replication of SNPs in all five genes and three plasma markers of energy homeostasis were associated with objective sleep measures. HIV disease influenced many of the associations. Findings strengthen evidence for associations between energy homeostasis genetics and poor sleep, and provide direction for pharmacological intervention research. 
Keywords: metabolism, adiponectin, leptin, ghrelin, peroxisome proliferator-activated receptor, actigraphy

\section{Highlights}

- Sleep disruption and duration are not independent sleep parameters.

- 17 SNPs from five candidate genes involved in energy homeostasis (ADIPOQ, GHRL, $L E P, P P A R A$, and PPARG) were associated with sleep disruption and/or duration in adults with HIV/AIDS.

- Higher plasma adiponectin was associated with less WASO; higher ghrelin and glucose levels were associated with shorter TST; and higher leptin was associated with longer TST.

- Poor sleep is prevalent in HIV-positive adults, and adjusting for HIV clinical indicators is important when assessing genetic associations with poor sleep.

- Results provide direction for developing precision pharmacologic therapy to improve sleep. 


\section{Introduction}

Sleep disturbance is a common symptom in chronic illness populations, and it is estimated that up to $75 \%$ of adults with human immunodeficiency virus/acquired immunodeficiency syndrome (HIV/AIDS) experience sleep problems [1]. Their most common sleep complaints are difficulty staying asleep [2-4] and short sleep duration [3, 5]. Energy metabolism has a reciprocal relationship with circadian clocks $[6,7]$, has been linked to poor sleep in animal models and humans [8-12], and is elevated in HIV-infected individuals [13, 14]. A genome-wide association study has also identified body mass index (BMI) relationships with self-reported long and short sleep duration [15]. However, research is limited on relationships between sleep parameters specifically using objective measures, and genes related to energy metabolism and energy balance in adults with HIV.

White adipose tissue (WAT) is the body's primary tissue for energy storage and has a major role in energy homeostasis. WAT secretes adiponectin, a peptide hormone involved in maintaining energy balance and regulating insulin sensitivity in liver and muscle. The expression of the adiponectin gene $(A D I P O Q)$ is inversely associated with total WAT mass and food intake (and therefore obesity). Insulin resistance, obesity, and type 2 diabetes are key components of metabolic syndrome, which we previously showed to be prevalent in the HIV/AIDS cohort also evaluated herein [16]. Leptin and ghrelin are also important peptide hormones involved in energy homeostasis. Like adiponectin, leptin is secreted by WAT and suppresses appetite, and therefore affects energy equilibrium. Ghrelin is secreted mainly in the gut and acts on the central nervous system to regulate appetite and energy balance. In humans, sleep duration is an important factor influencing leptin and ghrelin levels, and chronic short sleep duration is associated with low leptin and high ghrelin levels $[10,11,17]$. 
Two key transcriptional factors that regulate genes in fat metabolism are in the peroxisome proliferator-activated receptor (PPAR) family of nuclear receptors [18]. While PPAR-alpha (PPAR $\alpha$ ) is expressed chiefly in the liver, it is expressed at lower levels throughout the body [18]. PPAR-gamma (PPAR $\gamma$ ) is expressed mainly in WAT to control triglyceride storage and adipocyte differentiation and is associated with insulin sensitivity [18].

Variations in levels of adiponectin [19], ghrelin, leptin [20], PPAR $\alpha$ [21, 22] and PPAR $\gamma$ [19] have been reported in relation to sleep in animal models [19, 22] and humans [20]. Similarly, variations in levels of adiponectin [23], ghrelin [24], leptin [25], PPAR $\alpha$ [26], and PPAR $\gamma$ [27] have been reported in HIV-infected adults. Leptin [25], adiponectin [28], PPAR $\alpha$ and PPAR $\gamma$ [29] gene polymorphisms have also been associated with metabolic abnormalities in HIV-infected individuals. Similarly, gene polymorphisms in adiponectin[30], leptin [31], ghrelin [32], and PPAR $\gamma$ [33] have been associated with sleep-related phenotypes such as sleep duration or sleep apnea in other populations. However, no research to date has evaluated variations in biomarkers (i.e., single nucleotide polymorphisms, plasma levels) of these genes and objective sleep measures in the context of HIV infection, where sleep disturbance is prevalent and multifactorial.

The purpose of this study was to determine whether objectively measured sleep disruption and duration, in a sample of adults with HIV infection, are associated with single nucleotide polymorphisms (SNPs) in five select genes related to energy homeostasis (i.e., adiponectin $[A D I P O Q]$, ghrelin $[G H R L]$, leptin $[L E P], \operatorname{PPAR} \alpha[P P A R A], \operatorname{PPAR} \gamma[P P A R G])$ previously identified to be associated with sleep and HIV in other studies. We describe the relative contributions of variations in each gene to the variance in sleep disruption and duration. 
Finally, circulating levels of adiponectin, ghrelin, and leptin were evaluated to determine their relationships with sleep parameters and variations in energy homeostasis genes.

\section{Material and methods}

\subsection{Participants and setting}

The Symptom and Genetic Study was a longitudinal study aimed at identifying biomarkers (i.e., genetic, protein) of symptom experience among HIV-infected adults [34]. We previously reported the impact of circadian regulation and cytokine biomarkers on sleep and fatigue in adults with HIV [35-39]. This analysis focuses on a cross-sectional evaluation of genetic and plasma biomarkers of energy homeostasis and relationships to sleep outcomes at the initial visit, which was defined a priori. The Committee on Human Research at the University of California at San Francisco (UCSF) approved the study protocol. Participants were recruited using flyers posted at local HIV clinics and community sites. Participants provided written informed consent and signed a Health Insurance Portability and Accountability Act release to access their protected medical information. Study visits were conducted at the UCSF Clinical Research Center.

Eligible participants were English-speaking adults at least 18 years of age in whom HIV had been diagnosed at least 30 days before enrollment. To specifically address HIV-related symptom experience, potential participants were excluded if they currently used illicit drugs (as determined by self-report or positive urine drug testing); worked nights (i.e., between 24:00 and 06:00); reported bipolar disorder, schizophrenia, or dementia; or were pregnant within the prior 3 months. Participants were not excluded for insomnia, but were excluded for other diagnosed sleep disorders, such as apnea or narcolepsy. 


\subsection{Measures}

\subsubsection{Demographic, clinical, and laboratory characteristics}

A demographic questionnaire was used to collect information about the participant's age, gender, race, ethnicity, and employment status. Health history (i.e., time since HIV diagnosis, prior AIDS diagnosis) and current medication regimen were obtained by self-report. Medications were categorized as antiretroviral therapy, sleep medication, anxiolytic, antidepressant, neuroleptic, opiate, antiemetic, or anti-histamine based on their potential effect on sleep. Lifestyle factors likely to exacerbate sleep disturbance (smoking and daily consumption of caffeine and alcohol) were assessed using a 3-day diary. Trained research staff obtained waist circumference and body mass index (BMI; weight in kilograms divided by squared height in meters) during a visit to the Clinical Research Center. CD4+ T-cell count and HIV viral load values were obtained from the most recent laboratory report in the patient's medical record.

\subsubsection{Gene selection and genotyping}

Five candidate genes related to energy homeostasis were selected for analysis as part of the Symptom and Genetics Study. Genomic DNA was extracted from peripheral blood mononuclear cells and maintained by the UCSF Genomic Markers of Symptoms Tissue Bank [40, 41] using the PUREGene DNA Isolation System (Invitrogen, Carlsbad, CA). Of the 350 participants recruited, DNA could be isolated from 348.

Genotyping was performed blinded to clinical status and included positive and negative controls. DNA samples were quantitated with a Nanodrop Spectrophotometer (ND-1000; Thermo Fisher Scientific, Waltham, MA) and normalized to a concentration of $50 \mathrm{ng} / \mu \mathrm{L}$ (diluted in $10 \mathrm{mM}$ Tris/1 mM ethylenediaminetetraacetic acid [EDTA]). Samples were genotyped using the GoldenGate genotyping platform (Illumina, San Diego, CA) and processed according to the 
standard protocol using GenomeStudio (Illumina). Signal intensity profiles and resulting genotype calls for each SNP were visually inspected by two blinded reviewers. Disagreements were resolved by a third reviewer.

A combination of tagging SNPs and literature-driven SNPs (i.e., SNPs reported as being associated with altered function) were selected for analysis. Initially, SNPs reported in the literature as being associated with energy metabolism, sleep parameters, and/or HIV and its treatment in different studies were identified and forced into the tagSNP selection. Tagging SNPs were required to be common (defined as having a minor allele frequency $\geq 0.05$ ) in public databases (e.g., HapMap Phase I [http://www.hapmap.org]), were required to meet an $r^{2}$ cut-off of 0.85 , and informative in the major racial and ethnic groups represented in the cohort (i.e., African American, Caucasian, Hispanic) using Snagger for tagSNP selection [42]. In order to ensure robust genetic association analyses, quality-control filtering of SNPs was performed. All SNPs had call rates > 95\% and four SNPs were excluded with Hardy-Weinberg P values < 0.001. To maximize the power to detect genetic associations due to common genetic risk factors, SNPs with allele frequencies $<5 \%(\mathrm{n}=1)$ or with fewer than three individuals homozygous for the rare allele $(n=2)$ were also excluded from analysis. In order to control for potential confounding due to population substructure (e.g., race/ethnicity), 106 ancestry informative marker (AIM) SNPs selected to differentiate the common racial (i.e., African American, Caucasian) and ethnic (Hispanic) groups were genotyped. Twenty-three SNPs among the 5 candidate genes (i.e., ADIPOQ, GHRL, LEP, PPARA, PPARG) passed all quality-control filters and were included in the genetic association analyses.

\subsubsection{Plasma markers}


For selected plasma measures of energy homeostasis (leptin, ghrelin, adiponectin), blood samples were centrifuged and plasma was stored at $-80^{\circ} \mathrm{C}$ until samples were assayed. Insulin and C-peptide, which were included on a commercially designed analyte panel, were also evaluated. Samples were assayed in duplicate using the Luminex xMAP multiplex platform by Millipore, Inc (BioMarker Services, Millipore, St. Charles, MO), and the mean of the two assays was used for subsequent analyses. The within and between assay coefficients of variation were acceptable for leptin $(<10 \%$ and $<20 \%)$, ghrelin $(<10 \%$ and $<20 \%)$, adiponectin $(<10 \%$ and $<15 \%)$, insulin $(<10 \%$ and $<15 \%)$, and C-peptide $(<10 \%$ and $<15 \%)$. Fasting glucose levels were obtained from the participant's medical record.

\subsubsection{Actigraphy and sleep diary}

Sleep parameters were estimated with a noninvasive battery-operated wrist actigraph microprocessor with a piezoelectric beam that detects movement and acceleration (Mini Motionlogger Actigraph model AAM-32, Ambulatory Monitoring, Inc. Ardsley, NY). Actigraphy provides continuous movement counts and data were sampled in 30-sec epochs using zero-crossing mode. The actigraphy monitor was worn continuously on the nondominant wrist for $72 \mathrm{~h}$ on three consecutive weekdays between Monday and Friday to control for potential weekend variability and to reduce subject burden in this chronic illness population. Sleep diaries were also completed each morning and evening of the actigraphy monitoring period for the purpose of cross-validating bedtimes and wake times. Wrist actigraphy has been validated with polysomnography measures of sleep and wake time for healthy and disturbed sleepers [43-45]. Bedtime and final wake times were determined by one of two approaches: 1) participant pressing the event marker on the actigraph to indicate "lights out" and "lights on" or 2) if no reliable 
event marker indication, the diary entry of clock time was used if it matched with a $50 \%$ change in movement during the same 10-min block of time on actigraphy.

The primary sleep outcomes were wake after sleep onset (WASO) and total sleep time (TST) in minutes. The Cole-Kripke algorithm was used to calculate WASO and TST using an automatic sleep scoring program (Action4® Software Program, Ambulatory Monitoring Inc.) to reduce researcher scoring bias. WASO was standardized as a percentage of the person's TST to control for varying sleep durations. The intraclass correlation coefficient across the 3 nights was 0.83 for WASO and 0.76 for TST. The 3-night means for WASO and TST were used for all analyses.

\subsection{Statistical analysis}

All analyses were conducted using Stata (version 11.2, College Station, TX). Descriptive statistics were used to summarize demographic, clinical, and biomarker characteristics. To normalize skewed distributions, a square root transformation was applied to WASO and CD4+ T-cell counts, a log transformation was applied to HIV viral load, plasma ghrelin, and plasma leptin values, and an inverse transform (1/x) was applied to fasting glucose values. CD4+ T-cell count and HIV viral load were analyzed as continuous variables and also in clinically meaningful categories. Demographic and clinical associations with WASO and TST were evaluated using Spearman rho correlations, independent sample $t$-tests, or analysis of variance with Scheffé post hoc tests. Mann-Whitney U tests were used for group comparisons of plasma levels. Allele and genotype frequencies were determined by gene counting. Hardy-Weinberg equilibrium was assessed by the chi-square exact test.

\subsubsection{Genetic associations with sleep parameters}


Unadjusted genetic associations with WASO and TST were evaluated using linear regression models predicting the sleep parameter. Three genetic models (i.e., additive, dominant, recessive) were tested, and the model that best fit the data by maximizing the significance of the $\mathrm{P}$ value, barring trivial improvements (delta $<10 \%$ ), was reported for each SNP. All genetic regression models fitting genetic variations controlled for genomic estimates of ancestry (described below), as well as self-reported race/ethnicity (i.e., White/Caucasian, Black/African American, other), and all demographic, clinical, and laboratory variables associated $(\mathrm{P}<0.10)$ with the sleep parameter being predicted were evaluated as potential covariates. Variables were retained as covariates in all adjusted models if significant $(\mathrm{P}<0.05)$ prior to including genotype in the model. A model was fit for each genetic marker to estimate its contribution to WASO and TST when controlling for relevant demographic and clinical covariates. Given evidence that HIV interacts with many metabolic markers [46, 47], interactions between each genetic marker and measures of HIV exposure (i.e., HIV viral load, time since HIV diagnosis) were also evaluated.

\subsubsection{Associations between plasma markers and sleep parameters}

Unadjusted associations between plasma markers of energy homeostasis and WASO and TST were assessed using Spearman rho correlations. As in the genetic models, adjusted associations were evaluated using linear regression models predicting the sleep parameter while controlling for relevant demographic and clinical covariates. A model was fit for each plasma marker to estimate its contribution to the sleep parameter when controlling for relevant covariates. All regression models controlled for genomic estimates of ancestry (described below), as well as self-reported race/ethnicity (i.e., White/Caucasian, Black/African American, other). In addition, all demographic and clinical variables associated $(\mathrm{P}<0.10)$ with the sleep parameter being predicted were evaluated as potential covariates. Variables were retained as 
covariates in all adjusted models if their significance was $\mathrm{P}<0.05$ prior to including the plasma marker in the model. Given evidence that HIV interacts with many of these markers [46, 47], interactions between each plasma marker and measures of HIV exposure (i.e., HIV viral load, time since HIV diagnosis) were also evaluated. In addition, given the sex differences in many of the plasma markers [48, 49], interactions between gender (i.e., male, female, transgender) and each plasma marker were also evaluated. Differences in plasma markers were also evaluated for all genotypes associated with sleep parameters.

Ancestry informative markers (AIMs) are used to minimize potential bias due to population substructure [50-52]. Homogeneity in ancestry among participants was estimated by principal component analysis with orthogonal rotation [53] using HelixTree software (GoldenHelix, Bozeman, MT). With 106 AIMs included in this analysis, principal components (PC) were sought that distinguished the major racial/ethnic groups (i.e., White/Caucasian, Black/African American, Hispanic, other) by visual inspection of scatterplots of orthogonal PCs (e.g., PC1 versus PC2, PC2 versus PC3). The first three PCs were sufficient to distinguish the racial and ethnic groups and were included as covariates in all adjusted regression models to better control for genomic differences in ancestry.

\section{Results}

\subsection{Sample characteristics}

A convenience sample of 350 adults with HIV was enrolled in the study, and 61 participants were excluded prior to analysis due to screening positive for illicit drugs $(n=31)$, unable to submit a urine or blood sample ( $\mathrm{n}=2)$, and having incomplete or invalid actigraphy data ( $\mathrm{n}=28)$, An additional 12 participants were missing valid actigraphy data for the initial visit, and actigraphy data were used from a subsequent visit. Sample characteristics for the 289 
participants are in Table 1. The sample was ethnically diverse and predominantly male, reflecting the local population of adults with HIV. Participants had HIV for an average of $12 \pm 6.9$ years; most $(75 \%)$ were receiving medical disability assistance, $71 \%$ were currently receiving antiretroviral therapy, and they were taking 5.9 \pm 4.0 medications (median 6 , range 0 20).

Actigraphy measures indicated that the sample had short duration and substantial disruption. Almost half $(45 \%, \mathrm{n}=130)$ averaged $<6$ hours sleep at night, and 35\% $(\mathrm{n}=101)$ had WASO values that were $>25 \%$ of their sleep period. As shown in Table 1, the sleep parameters differed by both race and employment status. Of the clinical variables, CD4+ T-cell count was correlated with both WASO and TST, but the associations between viral load and these two sleep parameters did not reach statistical significance. Various categories of medication use were associated with WASO and TST, and smokers had shorter TST than non-smokers. BMI and waist circumference were associated with TST, but only among males. Participants who met diagnostic criteria for metabolic syndrome had more WASO, shorter TST, and worse selfreported sleep quality compared to participants without metabolic syndrome.

\subsection{Genetic associations with sleep disruption (WASO)}

Of the 23 SNPs examined, 10 SNPs among the 5 candidate genes were significantly associated with WASO in unadjusted analyses (Table 2). To better estimate the magnitude of the association between genotype and WASO when adjusting for relevant covariates, multiple linear regression models were fit. Genomic estimates of ancestry and self-reported race/ethnicity were forced into all models for face validity. Significant covariates from Table 1 included gender, the interaction of gender and race, CD4+ T-cell count, waist circumference, and use of opiate or antiemetic medication. Employment status, HIV viral load, BMI, and use of anti-depressant, 
neuroleptic, or sleep medication were also evaluated as potential covariates but did not meet the criterion for retention $(\mathrm{P}<0.05)$ in the model prior to inclusion of genotype. When the interaction was significant, the models also included two interaction terms between genotype and either viral load or years since HIV diagnosis.

In adjusted analyses, nine SNPs (ADIPOQ rs182052, rs1501299, rs3821799, and rs6773957; LEP rs10244329 and rs3828942; PPARA rs135551 and rs4253655; PPARG rs709151) were associated with WASO after adjusting for race/ethnicity, gender, CD4+ T-cell count, waist circumference, and medication use (Tables 3 and 4). Four of these SNPs (ADIPOQ rs182052, LEP rs10244329, PPARA rs135551, PPARG rs709151) did not interact with HIV variables, another four (ADIPOQ rs1501299, rs3821799, and rs6773957; LEP rs3828942) had a significant interaction with viral load, and one (PPARA rs4253655) had a significant interaction with years since diagnosis. Of the nine SNPs associated with WASO in adjusted analyses, four (ADIPOQ rs1501299, rs3821799, and rs6773957; LEP rs3828942) were not significant in unadjusted analyses. As shown in Table 4, the overall models for the nine SNPs associated with WASO explained $23.6-25.2 \%$ of the variance, with genotype accounting for $1.2-3.1 \%$ of the variance. None of the SNP asssociations observed for ADIPOQ, LEP, or PPARA were in high LD (i.e., all pairwise $\mathrm{LD}<0.5$ ). Adjusted differences in WASO by selected genotypes are shown in Figure 1.

\subsection{Genetic associations with sleep duration (TST)}

In unadjusted analyses (Table 2), TST was associated with 11 of 23 SNPs in 4 of the 5 energy homeostasis genes examined (ADIPOQ, GHRL, PPARA, and PPARG). Analyses adjusting for relevant covariates included genomic estimates of ancestry and self-reported race/ethnicity (both forced into the models), as well as gender, waist circumference, use of 
neuroleptic or antiemetic medication, and smoking; none of the other potential covariates met criteria $(\mathrm{P}<0.05)$ for retention in the model prior to inclusion of genotype. When genotype had a significant interaction with either viral load or years since HIV diagnosis, the interaction was also included in the model.

In adjusted analyses, 14 SNPs $(A D I P O Q$ rs182052 and rs2241766; GHRL rs26802; LEP rs10244329, rs11760956, and rs3828942; PPARA rs135551, rs135547, rs4253655, rs8138102, and rs4253776; PPARG rs12490265, rs796313, and rs709151) were associated with TST after adjusting for effects of race/ethnicity, gender, waist circumference, medication use, and smoking (Tables 3 and 4). Four of these SNPs (ADIPOQ rs182052; GHRL rs26802; PPARA rs135551 and rs135547) did not interact with HIV variables, five others (LEP rs3828942; PPARA rs8138102 and rs4253776; PPARG rs12490265 and rs796313) had a significant interaction with viral load, and the remaining five (ADIPOQ rs2241766; LEP rs10244329 and rs11760956; PPARA rs4253655; PPARG rs709151) had a significant interaction with years since diagnosis. As shown in Table 3, three SNPs (LEP rs10244329, PPARA rs4253655, PPARG rs12490265) were associated with TST regardless of whether a significant interaction with years since diagnosis was included in the model. For these SNPs, the model with the interaction is reported in Table 4. In addition, three SNPs (PPARA rs4253776; PPARG rs12490265 and rs709151) had significant interactions with both viral load and years since diagnosis (in separate models), and for these SNPs, the model with the largest F statistic is reported in Table 4. Of the 14 SNPs associated with TST in adjusted analyses, three (LEP rs11760956 and rs3828942; PPARA rs8138102) were not significant in unadjusted analyses. As shown in Table 4, the overall models for 14 SNPs associated with TST explained 19.7-23.2\% of the variance in TST, with genotype accounting for $1.4-4.5 \%$ of the variance. With the exception of PPARG rs12490265 rs709151 
$\left(r^{2}=0.55\right)$, none of the SNP asssociations observed for ADIPOQ, LEP, PPARA, or PPARG were in high LD (i.e., all pairwise LD<0.5). Adjusted differences in TST by selected genotypes are illustrated in Figure 2.

\subsection{Plasma markers}

Table 5 lists the correlations between the two sleep parameters and plasma markers of energy homeostasis. Higher glucose levels were associated with more WASO and shorter TST. To estimate the plasma markers' effects on sleep parameters when adjusting for relevant covariates, multiple linear regression models were fit for each plasma marker. Separate models were generated for WASO and TST, and the same covariates were used as in the genetic models described in Table 4. As shown in Table 6, WASO and plasma adiponectin values had a significant adjusted association that was moderated by viral load. Higher adiponectin levels were associated with less WASO, but higher viral loads attenuated this relationship. In addition, TST had significant adjusted associations with plasma ghrelin, leptin, and glucose, and these associations were also moderated by viral load. Higher plasma ghrelin and fasting glucose levels were associated with shorter TST, but higher viral loads attenuated this relationship. In contrast, higher plasma leptin levels were associated with longer TST, and higher viral loads attenuated this relationship as well.

\subsection{Differences in plasma marker levels by genotype}

Two of the SNPs associated with WASO or TST in Table 4 (PPARA rs135551 and rs135547) were also associated with fasting glucose levels ( $\mathrm{P}=0.011$, and 0.019 , respectively). For these two PPARA SNPs, each copy of the less common allele was associated with a higher fasting glucose value, as well as a shorter TST, and for PPARA rs135551, an increase in WASO. In addition, LEP rs10244329 associated with WASO and TST (Table 4) was also associated with 
plasma leptin levels $(\mathrm{P}=0.021)$. For this $L E P$ SNP, carriers of two copies of the less common allele had a higher plasma leptin level, as well as less WASO and longer TST, compared to carriers of the major allele.

\section{Discussion}

In this study of adults with HIV, 17 SNPs from five genes (ADIPOQ, GHRL, LEP, PPARA, PPARG) were associated with sleep disruption or duration after adjusting for genomic estimates of ancestry, self-reported race/ethnicity, and other relevant covariates. Of these 17 SNPs, six were associated with both WASO and TST. These findings are consistent with prior studies reporting associations between plasma biomarkers of energy homeostasis and selfreported measures of sleep quality and duration [12]. This association has also been demonstrated in individuals with obstructive sleep apnea (OSA) [54].

HIV-infection and its pharmacologic treatment are accompanied by metabolic perturbations and immune dysfunction. HIV-associated metabolic abnormalities include dyslipidemia, insulin resistance, metabolic syndrome, and diabetes. Adiponectin is an adipocytokine that acts as an insulin sensitizer of both skeletal muscle and hepatocytes. Hypoadiponectinemia is associated with obesity and insulin resistance and the association with metabolic syndrome may be independent of antiretroviral therapy in HIV-infected individuals [55]. The HIV tat protein down-regulates adiponection [56], and $A D I P O Q$ SNPs have been associated with OSA [30]. Variations in $A D I P O Q$ were associated with metabolic abnormalities in HIV-infected persons who had the $A D I P O Q$ rs $2241766 \mathrm{G}$ allele (i.e., carriers of the $\mathrm{G}$ allele: GT heterozygotes and GG homozygotes) associated with normolipidemic profiles in HIV/HCV co-infection with steatosis [57]. The A allele of $A D I P O Q$ rs 182052 was associated with type 2 diabetes in two different Chinese cohorts [58, 59], as well as lower adiponectin levels in multiple 
European samples [60-63]. Similarly, adults homozygous for the rs2241766 G allele are at lower risk for hypoadiponectinemia, type 2 diabetes [64], and obesity [65].

Only one study was found in which the association between $A D I P O Q$ SNPs (i.e., rs2241766) and measures of dyslipidemia were evaluated in an HIV-infected cohort [57]. While sleep parameters were not evaluated, the $G$ allele was protective; carriers of the $G$ allele had less risk of dyslipidemia. In the current study, two $A D I P O Q$ SNPs were associated with poor sleep in unadjusted analyses (i.e., carrying one or two copies of the rs182052 A allele with higher WASO and shorter TST; carrying two copies of the rs2241766 G allele with longer TST), and these associations remained significant after adjusting for relevant covariates (Table 4). Prior evidence of the influence of HIV infection on ADIPOQ functioning suggested that adjusting for HIV clinical variables in the current study was warranted and resulted in identifying three additional genetic associations (Table 4). These findings indicate that variations in $A D I P O Q$ are associated with poor sleep, but that HIV infection can influence these relationships.

Plasma adiponectin levels have been previously associated with TST [12] and OSA [54, 66]. In our study, higher adiponectin levels were associated with less WASO. Our findings suggest adiponectin may have anti-inflammatory effects on sleep disruption. However, higher viral loads attenuated this relationship in our sample and the association between plasma adiponectin and TST was complex and not evident after adjusting for gender. We confirmed prior findings that women have higher fasting adiponectin levels compared to men [67]. Simpson et al. found that sleep restriction altered adiponectin, but effects were moderated by both race and sex [68]. In animal models, sleep fragmentation has also been shown to alter adiponectin gene expression [69]. 
Plasma leptin and ghrelin levels have been associated with sleep duration [70, 71], and similar associations were also evident in our sample. Women have a higher fasting leptin level than men [67], which was also observed in our sample. Leptin is an adipokine with complex metabolic, neuroendocrine, and immune functions. Ghrelin influences satiety, food intake, and energy homeostasis. Although variations in $C L O C K$ gene have been associated with plasma ghrelin [72], associations between ghrelin gene variations and sleep parameters have not been reported. While leptin plasma levels do not appear to be associated with immunologic or virologic parameters in HIV-infected adults [73], plasma levels of ghrelin appear elevated in HIV-infected adults independent of BMI [74]. In the current study, one GHRL SNP was associated with better sleep (i.e., each additional copy of the rs $26802 \mathrm{G}$ allele with less WASO in unadjusted, and longer TST in unadjusted and adjusted models). One LEP SNP was associated with less disruption (i.e., two copies of the rs10244329 $\mathrm{T}$ allele with less WASO) in both unadjusted and adjusted models, and associated with shorter duration (i.e., two copies of the rs10244329 T allele with less TST controlling for an interaction with years since diagnosis) in adjusted models. Two additional LEP SNPs were associated with disruption (i.e., each additional copy of the rs11760956 A allele with more TST controlling for an interaction with years since diagnosis; one or two copies of the rs3828942 T allele with increased WASO controlling for an interaction with viral load) and/or TST (i.e., one or two copies of the rs3828942 T allele with shorter TST controlling for an interaction with years since diagnosis) in adjusted models. No studies were found that evaluated GHRL rs26802 and LEP rs10244329.

Evidence of the link between energy homeostasis and sleep continues to accumulate with findings regarding PPAR $\alpha$, a lipid-sensing transcription factor impacting metabolic and neurobiological processes, including sleep modulation [75]. In a rodent model, 
intrahypothalamic injection of a PPAR $\alpha$ agonist resulted in more wakefulness and less slow wave sleep while administration of a PPAR $\alpha$ antagonist produced opposite effects [75]. Manipulating PPAR $\alpha$ activity in murine models impacts both energy metabolism and sleep [7678]. In addition, PPAR $\alpha$ inhibits HIV tat protein-mediated up-regulation of inflammatory mediators [56]. In the current study, four PPARA SNPs were associated with worse sleep (more WASO or shorter TST) in unadjusted analyses: 1) each copy of the rs135551 G allele, 2) each copy of the rs135547 $\mathrm{C}$ allele, 3) two copies of the rs8138102 $\mathrm{G}$ allele, and 4) one or more copies of the rs $4253776 \mathrm{G}$ allele. All four associations were retained in adjusted models, with the rs8138102 and rs4253776 models controlling for an interaction with viral load. In contrast, carrying one or two copies of the rs4253655 A allele was associated with better sleep (less WASO and longer TST) in unadjusted models and adjusted models controlling for an interaction with years since diagnosis. Genetic associations between PPARA rs135547, rs4253655, and rs8138102 and sleep have not been reported in the literature. Consistent with reports of associations between PPARA and metabolic traits in the context of HIV-infection [76-78], HIV parameters also influenced the relationship between PPARA SNPs and sleep parameters in the current sample.

Similar to PPAR $\alpha$, PPAR $\gamma$ is also a central effector of lipid and energy homeostasis and influences inflammatory mediators. Variations in PPARG have been associated with body weight and dyslipidemia as well as OSA [79, 80]. In addition, several HIV viral proteins (env [81, 82], nef [83], gag [82], tat [84], vif [85]) interact directly with PPAR $\gamma$. Importantly, emerging evidence suggests that PPAR activation can protect against HIV-mediated cerebrovascular impairment [86]. PPAR $\gamma$ acts as a negative regulator of HIV viral replication [87]. PPARG rs12490265 G allele has been associated with metabolic syndrome [88]. In the current sample, 
four PPARG SNPs were associated with better sleep (less WASO and longer TST) in unadjusted analyses: 1) carriers of one or two copies of the rs12490265 A allele, 2) each additional copy of the rs4135247 A allele, 3) each additional copy of the rs796313 T allele in unadjusted models and one or two copies of the rs796313 T allele in adjusted models, and 4) carriers of one or two copies of the rs709151 T allele. Clinical HIV indicators (years since diagnosis and viral load) influenced the associations between PPARG SNPs and sleep parameters, a finding that supports reports of PPAR $\gamma$ impact on HIV pathogenesis. Genetic associations between PPARG rs4135247 and rs796313 and sleep have not been reported in the literature.

\subsection{Limitations}

The primary limitation of this research was the modest sample size for genetic associations, even with careful selection of the five candidate genes. We cannot rule out the possibility that some of the observered associations are not due to type I error (i.e., false positives). Further genome-wide association studies with larger samples are warranted with other energy homeostasis genes that may also be associated with sleep (e.g., LEPR, MC4R, PCSK1, POMC) [89]. A larger sample could provide more definitive estimates of the optimal genetic model (e.g., the additive model was optimal in unadjusted analyses for PPARA rs135551 associations with WASO, but the recessive model was optimal in adjusted models). A larger sample size may also identify additional SNP associations in the five candidate genes as well as other untested candidate genes. In addition, the small numbers of women, transgender, and racial subgroups precluded a thorough examination of how associations vary by sex, gender, and race. We included BMI and waist circumference as potential covariates, but did not assess food preferences or consumption, which may affect metabolic rate. Potential interactions between genetic, clinical, demographic, and environmental factors that might impact energy homeostatic 
processes and sleep parameters require further investigation in larger samples of adults with HIV and adults with other chronic diseases who experience sleep problems. Objective measures of sleep disruption and duration were strengths of this study, however, studies with gold-standard polysomnography would provide assessment of sleep stages as well as more accurate measures of WASO and TST.

\subsection{Conclusions}

In this study, SNPs in five genes involved in energy homeostasis were associated with sleep disturbance and/or duration after adjusting for relevant covariates. One $A D I P O Q$ SNP was associated with WASO and TST, three with WASO alone, and one with TST alone. Two LEP SNPs were associated with WASO and TST, and another SNP with TST alone. One GHRL SNP was associated with TST. Four PPARA SNPs were associated with WASO and TST, while one other PPARA SNP was associated with TST alone. Finally, three PPARG SNPs were associated with WASO and TST, and another PPARG SNP with TST alone.

Prospective studies are warranted to determine whether poor sleep affects energy homeostasis, if energy homeostasis affects poor sleep, or both. For example, fenofibrate, a PPAR $\alpha$ agonist used to improve triglycerides and cholesterol, showed preliminary efficacy for obstructive sleep apnea [90]. Given the demonstration that inclusion of fenofibrate with antiretroviral therapy to treat dyslipidemia in HIV-infected persons was superior to statin therapy [91], further studies to evaluate for concomittent impact on sleep are warranted. With pharmacological targets available for PPAR $\alpha$ as well as PPAR $\gamma$, leptin, and adiponectin to treat pathology related to energy metabolism, there is high potential for improving sleep in HIVinfected individuals. In addition, HIV-infected individuals with minor alleles associated with 
more WASO, or with shorter or longer TST, may be at risk for developing sleep disturbance, and these patients may specifically benefit from targeted therapeutic interventions.

\section{Acknowledgments}

This research was supported by a grant from the National Institute of Mental Health (NIMH, 5 R01 MH074358). Data collection was supported by the General Clinical Research Center in the UCSF CTSA (1 UL RR024131). The authors gratefully acknowledge the funding for Eeeseung Byun by the National Institutes of Health/National Institute of Nursing Research (T32 NR007088, K23 NR017404) and the Academic Senate at UCSF.

\section{References}

[1] Rubinstein ML, Selwyn PA. High prevalence of insomnia in an outpatient population with HIV infection. J Acquir Immune Defic Syndr Hum Retrovirol. 1998;19:260-5.

[2] Phillips KD, Sowell RL, Boyd M, Dudgeon WD, Hand GA. Sleep quality and health-related quality of life in HIV-infected African-American women of childbearing age. Qual Life Res. 2005; 14:959-70.

[3] Lee KA, Gay C, Portillo CJ, Coggins T, Davis H, Pullinger CR, et al. Types of sleep problems in adults living with HIV/AIDS. J Clin Sleep Med. 2012;8:67-75.

[4] Gamaldo CE, Spira AP, Hock RS, Salas RE, McArthur JC, David PM, et al. Sleep, function and HIV: A multi-method assessment. AIDS Behav. 2013;17:2808-15.

[5] Gamaldo CE, Gamaldo A, Creighton J, Salas RE, Selnes OA, David PM, et al. Evaluating sleep and cognition in HIV. J Acquir Immune Defici Syndr. 2013;63:609-16.

[6] Sahar S, Sassone-Corsi P. Regulation of metabolism: The circadian clock dictates the time. Trends Endocrinol Metab. 2012;23:1-8. 
[7] Mazzoccoli G, Pazienza V, Vinciguerra M. Clock genes and clock-controlled genes in the regulation of metabolic rhythms. Chronobiol Int. 2012;29:227-51.

[8] Marcheva B, Ramsey KM, Peek CB, Affinati A, Maury E, Bass J. Circadian clocks and metabolism. In: Kramer A, Merrow M, editors. Circadian Clocks. Berlin, Heidelberg: Springer Berlin Heidelberg; 2013. p. 127-55.

[9] Feng D, Lazar MA. Clocks, metabolism, and the epigenome. Mol Cell. 2012;47:158-67.

[10] Spiegel K, Tasali E, Penev P, Van Cauter E. Brief communication: Sleep curtailment in healthy young men is associated with decreased leptin levels, elevated ghrelin levels, and increased hunger and appetite. Ann of Intern Med. 2004;141:846-50.

[11] Chaput JP, Despres JP, Bouchard C, Tremblay A. Short sleep duration is associated with reduced leptin levels and increased adiposity: Results from the Quebec family study. Obesity (Silver Spring, Md). 2007;15:253-61.

[12] Al-Disi D, Al-Daghri N, Khanam L, Al-Othman A, Al-Saif M, Sabico S, et al. Subjective sleep duration and quality influence diet composition and circulating adipocytokines and ghrelin levels in teen-age girls. Endocr J. 2010;57:915-23.

[13] Chang E, Sekhar R, Patel S, Balasubramanyam A. Dysregulated energy expenditure in HIVinfected patients: A mechanistic review. Clin Infect Dis. 2007;44:1509-17.

[14] Kosmiski L. Energy expenditure in HIV infection. Am J Clin Nutr. 2011;94:1677s-82s.

[15] Jones SE, Tyrrell J, Wood AR, Beaumont RN, Ruth KS, Tuke MA, et al. Genome-Wide Association Analyses in 128,266 Individuals Identifies New Morningness and Sleep Duration Loci. PLoS Genet. 2016;12:e1006125.

[16] Pullinger CR, Aouizerat BE, Gay C, Coggins T, Movsesyan I, Davis H, et al. Metabolic abnormalities and coronary heart disease risk in human immunodeficiency virus-infected 
adults. Metab Syndr Relat Disord. 2010;8:279-86.

[17] Taheri S, Lin L, Austin D, Young T, Mignot E. Short sleep duration is associated with reduced leptin, elevated ghrelin, and increased body mass index. PLoS Med. 2004;1:e62.

[18] Tyagi S, Gupta P, Saini AS, Kaushal C, Sharma S. The peroxisome proliferator-activated receptor: A family of nuclear receptors role in various diseases. J Adv Pharm Technol Res. 2011;2:236-40.

[19] Barnea M, Chapnik N, Genzer Y, Froy O. The circadian clock machinery controls adiponectin expression. Mol Cell Endocrinol. 2015;399:284-7.

[20] Dashti HS, Scheer FA, Jacques PF, Lamon-Fava S, Ordovas JM. Short sleep duration and dietary intake: epidemiologic evidence, mechanisms, and health implications. Adv Nutr. 2015;6:648-59.

[21] Murillo-Rodriguez E. The role of nuclear receptor PPARalpha in the sleep-wake cycle modulation. A tentative approach for treatment of sleep disorders. Curr Drug Deliv. 2017;14:473-82.

[22] Mijangos-Moreno S, Poot-Ake A, Guzman K, Arankowsky-Sandoval G, Arias-Carrion O, Zaldivar-Rae J, et al. Sleep and neurochemical modulation by the nuclear peroxisome proliferator-activated receptor alpha (PPAR-alpha) in rat. Neurosci Res. 2016;105:65-9.

[23] Lake JE, Vo QT, Jacobson LP, Sacktor N, Miller EN, Post WS, et al. Adiponectin and interleukin-6, but not adipose tissue, are associated with worse neurocognitive function in HIV-infected men. Antivir Ther. 2015;20:235-44.

[24] Falasca K, Manigrasso MR, Racciatti D, Zingariello P, Dalessandro M, Ucciferri C, et al. Associations between hypertriglyceridemia and serum ghrelin, adiponectin, and IL-18 levels 
in HIV-infected patients. Ann Clin Lab Sci. 2006;36:59-66.

[25] Vanasse GJ, Jeong JY, Tate J, Bathulapalli H, Anderson D, Steen H, et al. A polymorphism in the leptin gene promoter is associated with anemia in patients with HIV disease. Blood. 2011;118:5401-8

[26] Shores NJ, Mendes-Correa MC, Maida I, Turner J, High KP, Babudieri S, et al. Hepatic peroxisome proliferator-activated receptor gamma and alpha-mRNA expression in HCVinfected adults is decreased by HIV co-infection and is also affected by ethnicity. Clinics (Sao Paulo, Brazil). 2015;70:790-6.

[27] Yeligar SM, Ward JM, Harris FL, Brown LAS, Guidot DM, Cribbs SK. Dysregulation of alveolar macrophage PPARgamma, NADPH Oxidases, and TGFbeta1 in otherwise healthy HIV-infected individuals. AIDS Res Hum Retroviruses. 2017;33:1018-26.

[28] Kato H, Ohata A, Samukawa S, Ueda A, Ishigatsubo Y. Effect of adiponectin-encoding gene ADIPOQ single nucleotide polymorphisms +45 and +276 on serum lipid levels after antiretroviral therapy in Japanese patients with HIV-1-infection. J Int Med Res. 2016;44:297-306.

[29] Nazih H, Raffi F, Taïeb A, Reynes J, Choutet P, Cassuto JP, et al. Peroxisome proliferator activating receptor alpha and gamma polymorphisms and metabolic abnormalities in HIVinfected patients receiving highly active antiretroviral therapy: The ANRS CO8 APROCOCOPILOTE study. AIDS Res Hum Retroviruses. 2012;28:393-9.

[30] Cao J, Su SC, Huang HP, Ding N, Yin M, Huang M, et al. A preliminary study on correlation between adiponectin genotype polymorphisms and obstructive sleep apnea hypopnea syndrome. Chin Med J. 2012;125:2094-8.

[31] Kroll C, Trombelli M, Schultz LF, El Rafihi-Ferreira R, Mastroeni MF. Association of LEP- 
rs7799039 and ADIPOQ-rs2241766 polymorphisms with sleep duration in preschool age children. Sleep Med. 2020;66:68-75.

[32] Krishnan M, Shelling AN, Wall CR, Mitchell EA, Murphy R, McCowan LME, et al. Geneby-environment interactions of the CLOCK, PEMT, and GHRELIN loci with average sleep duration in relation to obesity traits using a cohort of 643 New Zealand European children. Sleep Med. 2017;37:19-26.

[33] Kripke DF, Kline LE, Nievergelt CM, Murray SS, Shadan FF, Dawson A, et al. Genetic variants associated with sleep disorders. Sleep Med. 2015;16:217-24.

[34] Lee KA, Gay C, Portillo CJ, Coggins T, Davis H, Pullinger CR, et al. Symptom experience in HIV-infected adults: a function of demographic and clinical characteristics. J Pain Symptom Manage. 2009;38:882-93.

[35] Byun E, Gay CL, Portillo CJ, Pullinger CR, Aouizerat BE, Lee KA. Cytokine polymorphisms are associated with daytime napping in adults living with HIV. Sleep Med. 2017;32:162-70.

[36] Lee KA, Gay C, Byun E, Lerdal A, Pullinger CR, Aouizerat BE. Circadian regulation gene polymorphisms are associated with sleep disruption and duration, and circadian phase and rhythm in adults with HIV. Chronobiol Int. 2015;32:1278-93.

[37] Lee KA, Gay CL, Lerdal A, Pullinger CR, Aouizerat BE. Cytokine polymorphisms are associated with fatigue in adults living with HIV/AIDS. Brain Behav Immun. 2014;40:95103.

[38] Gay CL, Zak RS, Lerdal A, Pullinger CR, Aouizerat BE, Lee KA. Cytokine polymorphisms and plasma levels are associated with sleep onset insomnia in adults living with HIV/AIDS. Brain Behav Immun. 2015;47:58-65. 
[39] Lee KA, Gay C, Pullinger CR, Hennessy MD, Zak RS, Aouizerat BE. Cytokine polymorphisms are associated with poor sleep maintenance in adults living with human immunodeficiency virus/acquired immunodeficiency syndrome. Sleep. 2014;37:453-63.

[40] Aouizerat BE, Dodd M, Lee K, West C, Paul SM, Cooper BA, et al. Preliminary evidence of a genetic association between tumor necrosis factor alpha and the severity of sleep disturbance and morning fatigue. Biol Res Nurs. 2009;11:27-41.

[41] Miaskowski C, Dodd M, Lee K, West C, Paul SM, Cooper BA, et al. Preliminary evidence of an association between a functional interleukin- 6 polymorphism and fatigue and sleep disturbance in oncology patients and their family caregivers. J Pain Symptom Manage. 2010;40:531-44.

[42] Edlund CK, Lee WH, Li D, Van Den Berg DJ, Conti DV. Snagger: a user-friendly program for incorporating additional information for tagSNP selection. BMC Bioinformatics. 2008;9:174.

[43] Ancoli-Israel S, Clopton P, Klauber MR, Fell R, Mason W. Use of wrist activity for monitoring sleep/wake in demented nursing-home patients. Sleep. 1997;20:24-7.

[44] Cole RJ, Kripke DF, Gruen W, Mullaney DJ, Gillin JC. Automatic sleep/wake identification from wrist activity. Sleep. 1992;15:461-9.

[45] Lichstein KL, Stone KC, Donaldson J, Nau SD, Soeffing JP, Murray D, et al. Actigraphy validation with insomnia. Sleep. 2006;29:232-9.

[46] Giralt M, Domingo P, Guallar JP, Rodriguez de la Concepcion ML, Alegre M, Domingo JC, et al. HIV-1 infection alters gene expression in adipose tissue, which contributes to HIV1/HAART-associated lipodystrophy. Antivir Ther. 2006;11:729-40.

[47] Cotter EJ, Chew N, Powderly WG, Doran PP. HIV type 1 alters mesenchymal stem cell 
differentiation potential and cell phenotype ex vivo. AIDS Res Hum Retroviruses. 2011;27:187-99.

[48] de Castro MA, Baltar VT, Marchioni DM, Fisberg RM. Sex differences in serum leptin and its relation to markers of cardiometabolic risk in middle-aged adults: Evidence from a population-based study. Nutrition. 2015;31:491-7.

[49] Song HJ, Oh S, Quan S, Ryu OH, Jeong JY, Hong KS, et al. Gender differences in adiponectin levels and body composition in older adults: Hallym aging study. BMC Geriatr. 2014;14:8.

[50] Halder I, Shriver M, Thomas M, Fernandez JR, Frudakis T. A panel of ancestry informative markers for estimating individual biogeographical ancestry and admixture from four continents: utility and applications. Hum Mutat. 2008;29:648-58.

[51] Hoggart CJ, Parra EJ, Shriver MD, Bonilla C, Kittles RA, Clayton DG, et al. Control of confounding of genetic associations in stratified populations. Am J Hum Genet. 2003;72:1492-504.

[52] Tian C, Gregersen PK, Seldin MF. Accounting for ancestry: population substructure and genome-wide association studies. Hum Mol Genet. 2008;17:R143-50.

[53] Price AL, Patterson NJ, Plenge RM, Weinblatt ME, Shadick NA, Reich D. Principal components analysis corrects for stratification in genome-wide association studies. Nat Genet. 2006;38:904-9.

[54] Al Mutairi S, Mojiminiyi OA, Al Alawi A, Al Rammah T, Abdella N. Study of leptin and adiponectin as disease markers in subjects with obstructive sleep apnea. Dis Markers. $2014 ; 2014: 706314$

[55] Morimoto HK, Simao AN, de Almeida ER, Ueda LT, Oliveira SR, de Oliveira NB, et al. 
Role of metabolic syndrome and antiretroviral therapy in adiponectin levels and oxidative stress in HIV-1 infected patients. Nutrition. 2014;30:1324-30.

[56] Huang W, Rha GB, Han MJ, Eum SY, Andras IE, Zhong Y, et al. PPARalpha and PPARgamma effectively protect against HIV-induced inflammatory responses in brain endothelial cells. J Neurochem. 2008;107:497-509.

[57] Pineda-Tenor D, Berenguer J, Garcia-Broncano P, Jimenez-Sousa MA, FernandezRodriguez A, Diez C, et al. Association of adiponectin (ADIPOQ) rs2241766 polymorphism and dyslipidemia in HIV/HCV-coinfected patients. Eur J Clin Invest. 2014;44:453-62.

[58] Li ZP, Zhang M, Gao J, Zhou GY, Li SQ, An ZM. Relation between ADIPOQ Gene Polymorphisms and Type 2 Diabetes. Genes (Basel). 2015;6:512-9.

[59] Wang WL, Zhu H, Xie Y, Li J. Relation between ADIPOQ gene polymorphisms and type 2 diabetes in a Chinese population. Int J Clin Exp Med. 2015;8:6124-8.

[60] Alsaleh A, O'Dell SD, Frost GS, Griffin BA, Lovegrove JA, Jebb SA, et al. Single nucleotide polymorphisms at the ADIPOQ gene locus interact with age and dietary intake of fat to determine serum adiponectin in subjects at risk of the metabolic syndrome. Am J Clin Nutr. 2011;94:262-9.

[61] Henneman P, Aulchenko YS, Frants RR, Zorkoltseva IV, Zillikens MC, Frolich M, et al. Genetic architecture of plasma adiponectin overlaps with the genetics of metabolic syndrome-related traits. Diabetes Care. 2010;33:908-13.

[62] Kyriakou T, Collins LJ, Spencer-Jones NJ, Malcolm C, Wang X, Snieder H, et al. Adiponectin gene ADIPOQ SNP associations with serum adiponectin in two female populations and effects of SNPs on promoter activity. J of Hum Genet. 
2008;53:718-27.

[63] Richardson DK, Schneider J, Fourcaudot MJ, Rodriguez LM, Arya R, Dyer TD, et al. Association between variants in the genes for adiponectin and its receptors with insulin resistance syndrome (IRS)-related phenotypes in Mexican Americans. Diabetologia. 2006;49:2317-28.

[64] Tu Y, Yu Q, Fan G, Yang P, Lai Q, Yang F, et al. Assessment of type 2 diabetes risk conferred by SNPs rs2241766 and rs1501299 in the ADIPOQ gene, a case/control study combined with meta-analyses. Mol Cell Endocrinol. 2014;396:1-9.

[65] Alsaleh A, Crepostnaia D, Maniou Z, Lewis FJ, Hall WL, Sanders TA, et al. Adiponectin gene variant interacts with fish oil supplementation to influence serum adiponectin in older individuals. J Nutr. 2013;143:1021-7.

[66] Yoshikawa M, Yamauchi M, Fujita Y, Koyama N, Fukuoka A, Tamaki S, et al. The impact of obstructive sleep apnea and nasal CPAP on circulating adiponectin levels. Lung. 2014;192:289-95.

[67] Nascimento H, Vieira E, Coimbra S, Catarino C, Costa E, Bronze-da-Rocha E, et al. Adipokine Gene Single-Nucleotide Polymorphisms in Portuguese Obese Adolescents: Associations with Plasma Concentrations of Adiponectin, Resistin, IL-6, IL-1beta, and TNF-alpha. Child Obes. 2016;12:300-13.

[68] Simpson NS, Banks S, Arroyo S, Dinges DF. Effects of sleep restriction on adiponectin levels in healthy men and women. Physiol and Behav. 2010;101:693-8.

[69] Khalyfa A, Mutskov V, Carreras A, Khalyfa AA, Hakim F, Gozal D. Sleep fragmentation during late gestation induces metabolic perturbations and epigenetic changes in adiponectin gene expression in male adult offspring mice. Diabetes. 2014;63:3230-41. 
[70] Charles LE, Gu JK, Andrew ME, Violanti JM, Fekedulegn D, Burchfiel CM. Sleep duration and biomarkers of metabolic function among police officers. J Occup Environ Med. 2011;53:831-7.

[71] St-Onge MP, O'Keeffe M, Roberts AL, RoyChoudhury A, Laferrere B. Short sleep duration, glucose dysregulation and hormonal regulation of appetite in men and women. Sleep. 2012;35:1503-10.

[72] Garaulet M, Sanchez-Moreno C, Smith CE, Lee YC, Nicolas F, Ordovas JM. Ghrelin, sleep reduction and evening preference: relationships to CLOCK 3111 T/C SNP and weight loss. PLoS One. 2011;6:e17435.

[73] Tiliscan C, Arama V, Mihailescu R, Munteanu DI, Streinu-Cercel A, Ion DA, et al. Leptin expression in HIV-infected patients during antiretroviral therapy. Germs. 2015;5:92-8.

[74] Freitas P, Carvalho D, Santos AC, Madureira AJ, Martinez E, Pereira J, et al. Adipokines, hormones related to body composition, and insulin resistance in HIV fat redistribution syndrome. BMC Infect Dis. 2014;14:347.

[75] Mijangos-Moreno S, Poot-Ake A, Guzman K, Arankowsky-Sandoval G, Arias-Carrion O, Zaldivar-Rae J, et al. Sleep and neurochemical modulation by the nuclear peroxisome proliferator-activated receptor alpha (PPAR-alpha) in rat. Neurosci Res. 2016;105:65-9.

[76] Chikahisa S, Shimizu N, Shiuchi T, Sei H. Ketone body metabolism and sleep homeostasis in mice. Neuropharmacology. 2014;79:399-404.

[77] Chikahisa S, Tominaga K, Kawai T, Kitaoka K, Oishi K, Ishida N, et al. Bezafibrate, a peroxisome proliferator-activated receptors agonist, decreases body temperature and enhances electroencephalogram delta-oscillation during sleep in mice. Endocrinology. 2008;149:5262-71. 
[78] Shirai H, Oishi K, Kudo T, Shibata S, Ishida N. PPARalpha is a potential therapeutic target of drugs to treat circadian rhythm sleep disorders. Biochem Biophys Res Commun. 2007;357:679-82.

[79] Guan J, Yi H, Wu X, Su K, Tao M, Yin S. Pro12Ala polymorphism in human peroxisome proliferator activated receptor gamma is associated with hyperlipidaemia in obstructive sleep apnoea hypopnoea syndrome. J Laryngol Otol. 2011;125:1042-8.

[80] Bhushan B, Guleria R, Misra A, Luthra K, Kumar G. Association of PPARgamma2 (Pro12Ala) and neuropeptide Y (Leu7Pro) gene polymorphisms with obstructive sleep apnea in obese Asian Indians. Dis Markers. 2011;30:31-8.

[81] Gibellini D, Alviano F, Miserocchi A, Tazzari PL, Ricci F, Clo A, et al. HIV-1 and recombinant gp120 affect the survival and differentiation of human vessel wall-derived mesenchymal stem cells. Retrovirology. 2011;8:40.

[82] Cotter EJ, Malizia AP, Chew N, Powderly WG, Doran PP. HIV proteins regulate bone marker secretion and transcription factor activity in cultured human osteoblasts with consequent potential implications for osteoblast function and development. AIDS Res Hum Retroviruses. 2007;23:1521-30.

[83] Otake K, Omoto S, Yamamoto T, Okuyama H, Okada H, Okada N, et al. HIV-1 Nef protein in the nucleus influences adipogenesis as well as viral transcription through the peroxisome proliferator-activated receptors. AIDS. 2004;18:189-98.

[84] Huang W, Mo X, Wu X, Luo W, Chen Y. Rosiglitazone suppresses HIV-1 Tat-induced vascular inflammation via Akt signaling. Mol Cell Biochem. 2015;407:173-9.

[85] Kim DY, Kwon E, Hartley PD, Crosby DC, Mann S, Krogan NJ, et al. CBFbeta stabilizes HIV Vif to counteract APOBEC3 at the expense of RUNX1 target gene expression. Mol 
Cell. 2013;49:632-44.

[86] Huang W, Chen L, Zhang B, Park M, Toborek M. PPAR agonist-mediated protection against HIV Tat-induced cerebrovascular toxicity is enhanced in MMP-9-deficient mice. J Cereb Blood Flow Metab. 2014;34:646-53.

[87] Bernier A, Cleret-Buhot A, Zhang Y, Goulet JP, Monteiro P, Gosselin A, et al. Transcriptional profiling reveals molecular signatures associated with HIV permissiveness in Th1Th17 cells and identifies peroxisome proliferator-activated receptor gamma as an intrinsic negative regulator of viral replication. Retrovirology. 2013;10:160.

[88] Guo SX, Guo H, Ma RL, Ding YS, Zhang JY, Liu JM, et al. Analysis of the haplotype and linkage disequilibrium of PPARgamma gene polymorphisms rs3856806, rs12490265, rs1797912, and rs1175543 among patients with metabolic syndrome in Kazakh of Xinjiang Province. Genet Mol Res. 2014;13:8686-94.

[89] Nordang GBN, Busk OL, Tveten K, Hanevik HI, Fell AKM, Hjelmesaeth J, et al. Nextgeneration sequencing of the monogenic obesity genes LEP, LEPR, MC4R, PCSK1 and POMC in a Norwegian cohort of patients with morbid obesity and normal weight controls. Mol Genet Metab. 2017;121:51-6.

[90] Bruckert E, Duchêne E, Bonnefont-Rousselot D, Hansel B, Ansquer JC, Dubois A, et al. Proof of concept study: does fenofibrate have a role in sleep apnoea syndrome? Curr Med Res Opin. 2010;26:1185-92.

[91] Grandi AM, Nicolini E, Rizzi L, Caputo S, Annoni F, Cremona AM, et al. Dyslipidemia in HIV-positive patients: a randomized, controlled, prospective study on ezetimibe+fenofibrate versus pravastatin monotherapy. J Int AIDS Soc. 2014;17:19004. 
Table 1. Sleep parameters by demographic and clinical characteristics $(n=289)$

\begin{tabular}{|c|c|c|c|c|c|}
\hline & $\mathrm{N}$ & $\begin{array}{c}\mathrm{n}(\%) \text { or } \\
\text { mean }(S D)\end{array}$ & $\begin{array}{c}\text { WASO }(\%) \\
\text { mean }(S D) \text { or } r h o\end{array}$ & $\begin{array}{c}\text { TST (mins) } \\
\text { mean }(S D) \text { or rho }\end{array}$ & Statistics (when $\mathrm{P}<0.10$ ) \\
\hline Age, years (range 22-77) & 289 & $44.9(8.4)$ & $r h o=.028$ & $r h o=-.047$ & \\
\hline Gender & 289 & & & & \\
\hline Male & & $193(67 \%)$ & $21.0(15.5)$ & $369(100)$ & \\
\hline Female & & $73(25 \%)$ & $19.0(12.5)$ & $384(97)$ & \\
\hline Transgender & & $23(8 \%)$ & $25.1(15.0)$ & $349(96)$ & \\
\hline Race & 289 & & & & WASO: $F(2,286)=11.4, P<0.001$ \\
\hline Caucasian (C) & & $118(41 \%)$ & $16.1(12.0)$ & 407 (93) & $\mathbf{C}<\mathbf{A A} \& \mathbf{O}$ \\
\hline African American (AA) & & $110(38 \%)$ & $24.6(14.4)$ & $339(92)$ & TST: $F(2,286)=15.4, P<0.001$ \\
\hline Other $(\mathrm{O})$ & & $61(21 \%)$ & $23.1(17.8)$ & $358(99)$ & C > AA \& O \\
\hline Employment & 289 & & & & WASO: $t(287)=3.15, P=0.002$ \\
\hline Employed or in school & & $46(16 \%)$ & $15.3(12.9)$ & $395(85)$ & TST: $\mathrm{t}(287)=1.79, \mathrm{P}=0.075$ \\
\hline Unemployed or on disability & & $243(84 \%)$ & $21.9(14.9)$ & $366(101)$ & \\
\hline CD4+ T-cell count $($ cells/mm³) & 276 & & & & WASO: $\mathbf{P}=\mathbf{0 . 0 0 6}$ \\
\hline Mean $(S D)$ & & $453(267)$ & $r h o=-.166$ & $r h o=.183$ & TST: $\mathbf{P}=0.002$ \\
\hline$<200$ & & $47(17 \%)$ & $23.5(15.2)$ & $350(93)$ & \\
\hline$\geq 200$ & & $229(83 \%)$ & $20.2(14.6)$ & 374 (99) & \\
\hline Viral load $\left(\log _{10}\right.$ copies/mL) & 270 & & & & \\
\hline Mean $(S D)$ & & $2.64(1.20)$ & $r h o=.102$ & $r h o=-.107$ & WASO: $\mathrm{P}=0.096 ;$ TST: $\mathrm{P}=0.078$ \\
\hline Detectable & & $133(49 \%)$ & $22.5(16.0)$ & $361(103)$ & WASO: $\mathrm{t}(268)=1.87, \mathrm{P}=0.062$ \\
\hline Undetectable & & $137(51 \%)$ & $18.7(13.0)$ & $382(93)$ & TST: $\mathrm{t}(268)=1.78, \mathrm{P}=0.077$ \\
\hline Antiretroviral therapy & 289 & & & & \\
\hline Not on treatment & & $85(29 \%)$ & $21.9(13.3)$ & $367(96)$ & \\
\hline On treatment & & $204(71 \%)$ & $20.4(15.3)$ & $373(100)$ & \\
\hline Neuroleptic medication use & 288 & & & & WASO: $\mathrm{t}(286)=1.74, \mathrm{P}=0.083$ \\
\hline No & & $261(91 \%)$ & $21.3(15.1)$ & 367 (99) & TST: $t(286)=2.15, P=0.033$ \\
\hline Yes & & $27(9 \%)$ & $15.5(9.5)$ & $410(93)$ & \\
\hline Opiate medication use & 288 & & & & WASO: $\mathrm{t}(286)=3.40, \mathrm{P}<0.001$ \\
\hline No & & $210(73 \%)$ & $19.1(14.3)$ & $374(95)$ & \\
\hline Yes & & $78(27 \%)$ & $25.2(15.2)$ & $364(108)$ & \\
\hline
\end{tabular}




\begin{tabular}{|c|c|c|c|c|c|}
\hline Antiemetic medication use & 288 & & & & WASO: $t(286)=2.67, P=0.008$ \\
\hline No & & $277(96 \%)$ & $20.3(14.5)$ & $374(97)$ & TST: $t(286)=2.24, P=0.026$ \\
\hline Yes & & $11(4 \%)$ & $32.6(15.9)$ & $306(121)$ & \\
\hline Smoker? & 288 & & & & WASO: $\mathrm{t}(286)=1.71, \mathrm{P}=0.088$ \\
\hline No & & $125(53 \%)$ & $19.1(13.8)$ & $386(91)$ & TST: $t(286)=2.21, P=0.028$ \\
\hline Yes & & $163(57 \%)$ & $22.1(15.4)$ & $360(103)$ & \\
\hline Body mass index, $\mathrm{kg} / \mathrm{m}^{2}$ & 289 & $27.0(5.5)$ & & & \\
\hline Male $(\mathrm{M})$ & 193 & $26.0(4.8)$ & $r h o=.137$ & $r h o=-.252$ & M: WASO P $=0.058$, TST $\mathbf{P}<\mathbf{0 . 0 0 1}$ \\
\hline Female $(\mathrm{F})$ & 73 & $29.0(6.3)$ & $r h o=.114$ & rho $=.023$ & \\
\hline Transgender $(\mathrm{T})$ & 23 & $28.9(6.8)$ & $r h o=-.079$ & $r h o=.163$ & \\
\hline Waist circumference $(\mathrm{cm})$ & 289 & $93.7(12.9)$ & & & \\
\hline Male (M) & 193 & $93.7(12.4)$ & $r h o=.121$ & $r h o=-.204$ & M: WASO P=0.093, TST P=0.004 \\
\hline Female $(\mathrm{F})$ & 73 & $93.1(14.1)$ & $r h o=.215$ & $r h o=-.079$ & $\mathrm{~F}: \quad$ WASO $\mathrm{P}=0.067$ \\
\hline Transgender $(\mathrm{T})$ & 23 & $95.6(13.4)$ & $r h o=-.026$ & $r h o=.157$ & \\
\hline
\end{tabular}

WASO and CD4+ T-cell count analyses were conducted with square root-transformed values. WASO and TST were unrelated to use of anxiolytic, hypnotic, or antidepressant medications and to consumption of alcohol or caffeine (data not shown). Bolded variables have associations with P <0.05. P, P-value; SD, standard deviation; t, t statistic; TST, total sleep time; WASO, wake after sleep onset. 
Table 2. Unadjusted genetic associations with sleep parameters $(n=289)$

\begin{tabular}{|c|c|c|c|c|c|c|c|c|c|}
\hline \multirow[b]{2}{*}{$\begin{array}{r}G E N E \\
\text { SNP }\end{array}$} & \multirow[b]{2}{*}{ HGVS Description } & \multirow[b]{2}{*}{$\begin{array}{c}\text { HuRef } \\
\text { Position }\end{array}$} & \multirow[b]{2}{*}{ MAF } & \multicolumn{3}{|c|}{ WASO } & \multicolumn{3}{|c|}{ TST } \\
\hline & & & & $\mathrm{b}$ & SE & $\begin{array}{c}\mathrm{P} \\
\text { (Model) }\end{array}$ & $\mathrm{b}$ & SE & $\begin{array}{c}\mathrm{P} \\
\text { (Model) }\end{array}$ \\
\hline \multicolumn{10}{|l|}{$A D I P O Q$} \\
\hline $\mathbf{r s} 182052^{\mathrm{e}}$ & NG_021140.1:g.5320G $>A$ & $3: 186842993$ & 0.359 & 0.517 & 0.192 & 0.007 (D) & -30.55 & 11.70 & 0.010 (D) \\
\hline rs $12495941^{\mathrm{d}, \mathrm{e}}$ & NG_021140.1:g.12718G $>\mathrm{T}$ & $3: 186850391$ & 0.357 & -0.252 & 0.262 & $0.337(\mathrm{R})$ & 24.91 & 15.88 & $0.118(\mathrm{R})$ \\
\hline rs7649121 $1^{\mathrm{a}, \mathrm{b}, \mathrm{d}, \mathrm{e}}$ & NG_021140.1:g.13323A>T & $3: 186850996$ & 0.011 & - & - & - & - & - & - \\
\hline $\operatorname{rs}^{2241766^{e}}$ & $\begin{array}{l}\text { NG_021140.1:g.15430T }>G \text {, } \\
\text { NM_001177800.1:c.45T }>G \text {, } \\
\text { XP_011511626.1:p.Gly15 }\end{array}$ & 3:186853103 & 0.119 & 0.699 & 0.820 & $0.395(\mathrm{R})$ & 26.03 & 12.74 & $0.042(\mathrm{~A})$ \\
\hline rs $1501299^{\mathrm{d}, \mathrm{e}}$ & NG_021140.1:g.15661G $>\mathrm{T}$ & $3: 186853334$ & 0.298 & -0.225 & 0.315 & $0.474(\mathrm{R})$ & -6.67 & 11.70 & $0.569(\mathrm{D})$ \\
\hline rs $3821799^{d}$ & NG_021140.1:g.16024T $>C$ & $3: 186853697$ & 0.493 & 0.191 & 0.217 & 0.378 (D) & -4.97 & 8.08 & $0.539(\mathrm{~A})$ \\
\hline rs6773957 & NG_021140.1:g.18243A $>\mathrm{G}$ & $3: 186855916$ & 0.474 & 0.192 & 0.210 & $0.363(\mathrm{D})$ & -5.48 & 12.79 & 0.669 (D) \\
\hline \multicolumn{10}{|l|}{ GHRL } \\
\hline rs26802 $2^{\mathrm{d}, \mathrm{e}}$ & NG_033090.1:g.14730T>G & $3: 10290681$ & 0.332 & -0.312 & 0.143 & $0.031(\mathbf{A})$ & 31.29 & 11.66 & 0.008 (D) \\
\hline \multicolumn{10}{|l|}{ LEP } \\
\hline $\mathrm{rs} 12706832^{\mathrm{d}}$ & NG_007450.1:g.10809A>G & $7: 128247086$ & 0.415 & -0.222 & 0.131 & $0.091(\mathrm{~A})$ & 12.19 & 7.94 & $0.126(\mathrm{~A})$ \\
\hline rs10244329 ${ }^{\mathrm{d}, \mathrm{e}}$ & NG_007450.1:g.12359A $>\mathrm{T}$ & $7: 128248636$ & 0.483 & -0.460 & 0.219 & $0.037(\mathbf{R})$ & 21.07 & 13.38 & $0.116(\mathrm{R})$ \\
\hline rs11760956 & NG_007450.1:g.14757G $>A$ & $7: 128251034$ & 0.289 & -0.546 & 0.317 & $0.086(\mathrm{R})$ & 34.68 & 19.25 & $0.073(\mathrm{R})$ \\
\hline rs $3828942^{\mathrm{d}}$ & NG_007450.1:g.17975G $>$ A & $7: 128254252$ & 0.328 & -0.489 & 0.289 & $0.092(\mathrm{R})$ & 32.70 & 17.56 & $0.064(\mathrm{R})$ \\
\hline \multicolumn{10}{|l|}{ PPARA } \\
\hline $\mathrm{rs} 4253623^{\mathrm{e}}$ & NG_012204.1:g.8608A>G & $22: 46154203$ & 0.117 & -0.130 & 0.212 & $0.541(\mathrm{~A})$ & 20.54 & 12.84 & $0.111(\mathrm{~A})$ \\
\hline $\mathbf{r s}_{135551^{\mathrm{d}}}$ & NG_012204.1:g.11523A>G & $22: 46157126$ & 0.385 & 0.360 & 0.128 & $0.005(\mathrm{~A})$ & -26.66 & 7.72 & $0.001(\mathrm{~A})$ \\
\hline $\operatorname{rs} 135547^{\mathrm{d}}$ & NG_012204.1:g.12152G $>C$ & $22: 46157755$ & 0.430 & 0.401 & 0.124 & 0.001 (A) & -29.09 & 7.49 & $<0.001(\mathrm{~A})$ \\
\hline rs4253655 & NG_012204.1:g.27673G $>A$ & $22: 46173274$ & 0.097 & -0.581 & 0.247 & 0.019 (D) & 58.27 & 14.74 & $<0.001$ (D) \\
\hline rs9626736 $6^{c, d}$ & NG_012204.1:g.28734A>G & $22: 46174335$ & 0.438 & - & - & - & - & - & - \\
\hline${\mathbf{r s} 8138102^{\mathrm{d}}}$ & NG_012204.1:g.50254A $>\mathrm{G}$ & $22: 46195855$ & 0.299 & 0.610 & 0.309 & $0.049(R)$ & -32.55 & 18.79 & $0.084(\mathrm{R})$ \\
\hline rs $6007662^{\mathrm{c}, \mathrm{d}}$ & NG_012204.1:g.79547A>G & $22: 46225148$ & 0.415 & - & - & - & - & - & - \\
\hline $\mathrm{rs} 4253760^{\mathrm{cd}}$ & NG_012204.1:g.80886T $>\mathrm{G}$ & $22: 46226487$ & 0.382 & - & - & - & - & - & - \\
\hline rs4253776 & NG_012204.1:g.87981A $>\mathrm{G}$ & $22: 46233582$ & 0.256 & 0.307 & 0.194 & $0.114(\mathrm{D})$ & -24.52 & 11.73 & 0.037 (D) \\
\hline rs $4253778^{\mathrm{c}, \mathrm{d}}$ & NG_012204.1:g.89136G $>C$ & $22: 46234737$ & 0.382 & - & - & - & - & - & - \\
\hline
\end{tabular}




\begin{tabular}{|c|c|c|c|c|c|c|c|c|c|}
\hline \multirow[b]{2}{*}{$\begin{array}{r}\text { GENE } \\
\text { SNP }\end{array}$} & \multirow[b]{2}{*}{ HGVS Description } & \multirow[b]{2}{*}{$\begin{array}{c}\text { HuRef } \\
\text { Position }\end{array}$} & \multirow[b]{2}{*}{ MAF } & \multicolumn{3}{|c|}{ WASO } & \multicolumn{3}{|c|}{ TST } \\
\hline & & & & $\mathrm{b}$ & SE & $\begin{array}{c}\mathrm{P} \\
\text { (Model) }\end{array}$ & $\mathrm{b}$ & SE & $\begin{array}{c}\mathrm{P} \\
\text { (Model) }\end{array}$ \\
\hline \multicolumn{10}{|l|}{ PPARG } \\
\hline rs $2972164^{\mathrm{d}}$ & NG_011749.1:g.10068T >C & $3: 12292917$ & 0.423 & -0.204 & 0.133 & $0.126(\mathrm{~A})$ & 13.20 & 12.25 & $0.282(\mathrm{D})$ \\
\hline $\operatorname{rs}_{12490265^{d}}$ & NG_011749.1:g.60194G>A & $3: 12343043$ & 0.217 & -0.612 & 0.196 & 0.002 (D) & 38.51 & 11.88 & 0.001 (D) \\
\hline rs $1801282^{\mathrm{b}, \mathrm{e}}$ & $\begin{array}{l}\text { NG_011749.1:g.68777C }>\mathrm{G} \\
\text { NM_015869.4:c.34C>G, } \\
\text { XP_011532145.1:p.Pro12Ala }\end{array}$ & $3: 12351626$ & 0.056 & - & - & - & - & - & - \\
\hline rs4135247 ${ }^{\mathrm{d}}$ & NG_011749.1:g.72240G >A & $3: 12355089$ & 0.317 & -0.093 & 0.143 & $0.517(\mathrm{~A})$ & 28.11 & 8.52 & $0.001(\mathrm{~A})$ \\
\hline rs $4135275^{\mathrm{d}}$ & NG_011749.1:g.119496A>G & $3: 12402345$ & 0.146 & -0.292 & 0.735 & $0.691(\mathrm{R})$ & 15.41 & 11.86 & $0.195(\mathrm{~A})$ \\
\hline rs796313 & NG_011749.1:g.125180G > T & $3: 12408029$ & 0.448 & -0.356 & 0.132 & 0.007 (A) & 29.43 & 12.43 & 0.019 (D) \\
\hline rs709151 $^{\mathrm{d}}$ & NG_011749.1:g.130651C>T & $3: 12413500$ & 0.256 & -0.759 & 0.187 & $<0.001$ (D) & 50.41 & 11.31 & $<0.001$ (D) \\
\hline
\end{tabular}

Analyses were conducted with square root-transformed WASO values. Bold SNPs have associations with $\mathrm{P}<0.05$. A, additive model; $A D I P O Q$, adiponectin gene; $\mathrm{b}$, regression coefficient; $\mathrm{Chr}$, chromosome; $\mathrm{CI}$, confidence interval; $\mathrm{D}$, dominant model; GHRL, ghrelin gene; HGVS, human genome variation society; HuRef, human reference sequence; $L E P$, leptin gene; MAF, minor allele frequency; $\mathrm{P}$, P-value; PPARA, peroxisome proliferator-activated receptor alpha gene; PPARG, peroxisome proliferator-activated receptor gamma gene; R, recessive model; SE, standard error; SNP, single nucleotide polymorphism; TST, total sleep time; WASO, wake after sleep onset.

${ }^{\text {a }}$ SNP excluded from analysis because MAF $<0.05(n=1)$.

${ }^{\mathrm{b}}$ SNP excluded from analysis because one of the genotypes had a frequency $<3(\mathrm{n}=2)$.

${ }^{c}$ SNP excluded from analysis because distribution violated Hardy-Weinberg equilibrium $(n=4)$.

d tagSNP

${ }^{\mathrm{e}}$ Minor allele frequency difference of less than approximately $10 \%$ between Caucasian non-Hispanic and African American non-
Hispanic
population
samples
deposited
in
$\mathrm{dbSNP}$
(https://www.ncbi.nlm.nih.gov/snp/). 
Table 3. Patterns of associations between genotypes, their interactions with HIV, and sleep parameters

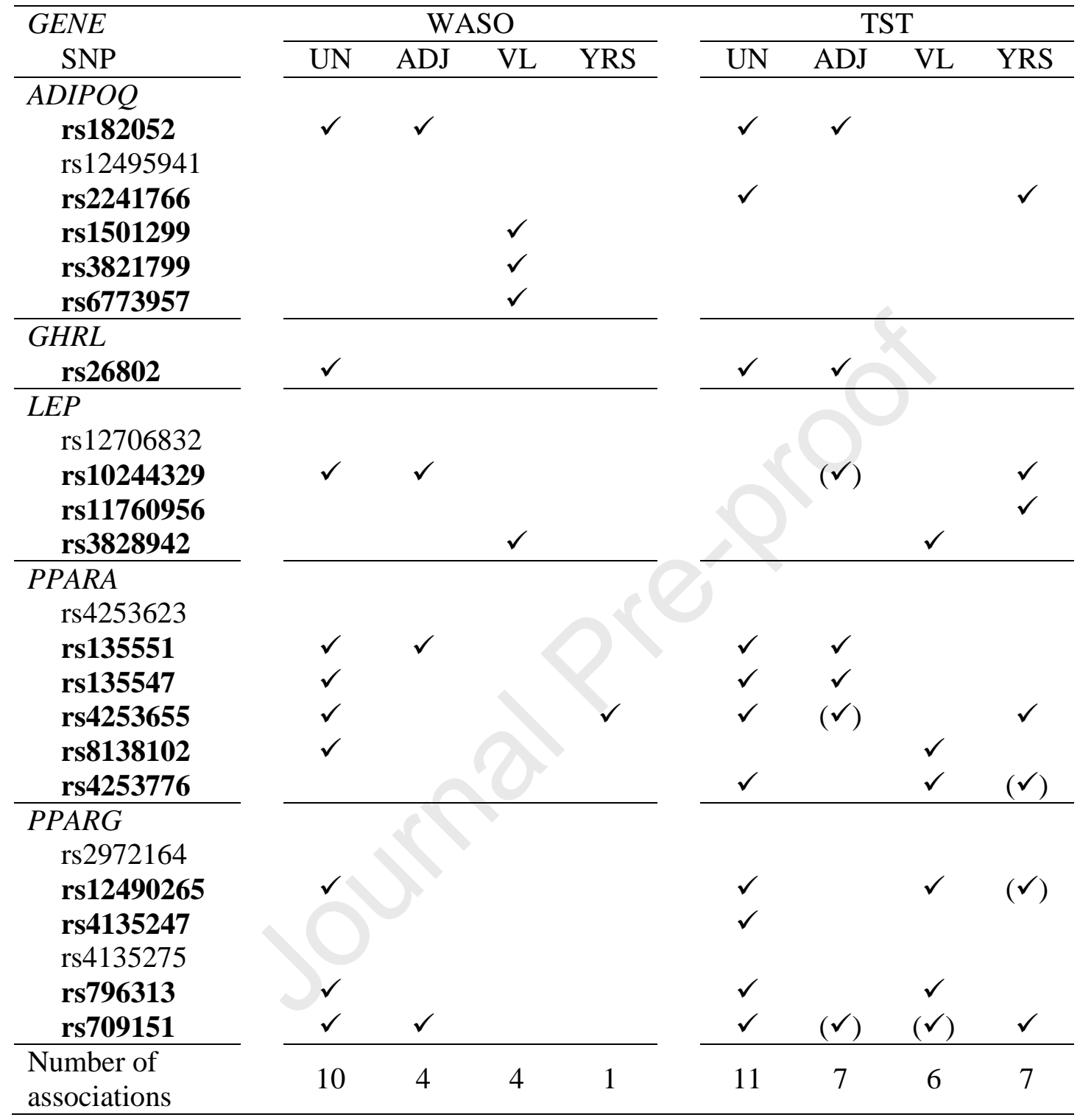

ADIPOQ, adiponectin gene; ADJ, genotype was significant in adjusted analyses and did not interact with either viral load or years since HIV diagnosis; GHRL, ghrelin gene; LEP, leptin gene; PPARA, peroxisome proliferator-activated receptor alpha gene; PPARG, peroxisome proliferator-activated receptor gamma gene; SNP, single nucleotide polymorphism; TST, total sleep time; UN, genotype was significant in unadjusted analyses; VL, genotype had a significant interaction with viral load in adjusted analyses; WASO, wake after sleep onset (square roottransformed); YRS, genotype had a significant interaction with years since HIV diagnosis in adjusted analyses; $\checkmark$, significant association; $(\checkmark)$, significant association but not as strong as one of the other adjusted models. Bold SNPs have at least one association with $\mathrm{P}<0.05$ 
Table 4. Significant adjusted associations between genotype and sleep parameters

\begin{tabular}{|c|c|c|c|c|c|c|c|c|}
\hline $\begin{array}{l}\text { Sleep outcome / GENE } \\
\text { SNP / *interaction }\end{array}$ & Model & $\mathrm{b}$ & SE & $\mathrm{t}$ & $\mathrm{P}$ & $\Delta \mathrm{R}^{2}$ & $\mathrm{R}^{2}$ & Full models \\
\hline \multicolumn{9}{|l|}{ WASO } \\
\hline \multicolumn{9}{|l|}{$A D I P O Q$} \\
\hline rs 182052 & $\mathrm{D}$ & 0.44 & 0.18 & 2.45 & 0.015 & 0.018 & 0.247 & $F(16,255)=5.23, P<0.001$ \\
\hline rs $1501299^{a}$ & $\mathrm{D}$ & -1.25 & 0.44 & 2.85 & 0.005 & 0.000 & 0.246 & $\mathrm{~F}(18,248)=4.49, \mathrm{P}<0.001$ \\
\hline VL*rs1501299 & & 0.46 & 0.15 & 3.03 & 0.003 & 0.028 & & \\
\hline rs3821799 ${ }^{a}$ & $\mathrm{R}$ & 1.07 & 0.50 & 2.15 & 0.032 & 0.001 & 0.241 & $\mathrm{~F}(18,248)=4.37, \mathrm{P}<0.001$ \\
\hline VL*rs3821799 & & -0.46 & 0.17 & 2.67 & 0.008 & 0.022 & & \\
\hline rs6773957 ${ }^{\mathrm{a}}$ & $\mathrm{D}$ & -1.12 & 0.47 & 2.36 & 0.019 & 0.001 & 0.243 & $\mathrm{~F}(18,248)=4.41, \mathrm{P}<0.001$ \\
\hline VL*rs6773957 & & 0.47 & 0.17 & 2.82 & 0.005 & 0.024 & & \\
\hline \multicolumn{9}{|l|}{ LEP } \\
\hline rs10244329 & $\mathrm{R}$ & -0.50 & 0.21 & 2.40 & 0.017 & 0.017 & 0.240 & $\mathrm{~F}(16,256)=5.06, \mathrm{P}<0.001$ \\
\hline rs $3828942^{\mathrm{a}}$ & $\mathrm{D}$ & 0.85 & 0.45 & 1.89 & 0.059 & 0.000 & 0.236 & $\mathrm{~F}(18,247)=4.23, \mathrm{P}<0.001$ \\
\hline VL*rs3828942 & & -0.35 & 0.16 & 2.26 & 0.024 & 0.016 & & \\
\hline \multicolumn{9}{|l|}{ PPARA } \\
\hline $\mathrm{rs} 135551^{\mathrm{b}}$ & $\mathrm{R}$ & 0.51 & 0.26 & 2.00 & 0.046 & 0.012 & 0.237 & $\mathrm{~F}(16,255)=4.96, \mathrm{P}<0.001$ \\
\hline rs4253655 & $\mathrm{D}$ & -1.81 & 0.62 & 2.93 & 0.004 & 0.012 & 0.252 & $\mathrm{~F}(18,254)=4.75, \mathrm{P}<0.001$ \\
\hline YRS*rs4253655 & & 0.09 & 0.04 & 2.31 & 0.022 & 0.016 & & \\
\hline \multicolumn{9}{|l|}{ PPARG } \\
\hline rs709151 & $\mathrm{D}$ & -0.50 & 0.71 & 2.68 & 0.008 & 0.021 & 0.245 & $\mathrm{~F}(16,256)=5.18, \mathrm{P}<0.001$ \\
\hline \multicolumn{9}{|l|}{ TST } \\
\hline \multicolumn{9}{|l|}{$A D I P O Q$} \\
\hline rs 182052 & $\mathrm{D}$ & -24.37 & 11.03 & 2.21 & 0.028 & 0.014 & 0.205 & $\mathrm{~F}(12,272)=5.86, \mathrm{P}<0.001$ \\
\hline rs2241766 & $\mathrm{R}$ & -114.03 & 72.00 & 1.58 & 0.114 & 0.002 & 0.210 & $\mathrm{~F}(14,270)=5.13, \mathrm{P}<0.001$ \\
\hline YRS*rs2241766 & & 14.41 & 5.42 & 2.66 & 0.008 & 0.021 & & \\
\hline \multicolumn{9}{|l|}{ GHRL } \\
\hline rs26802 & $\mathrm{D}$ & 26.84 & 10.98 & 2.44 & 0.015 & 0.018 & 0.205 & $\mathrm{~F}(12,272)=5.85, \mathrm{P}<0.001$ \\
\hline \multicolumn{9}{|r|}{ 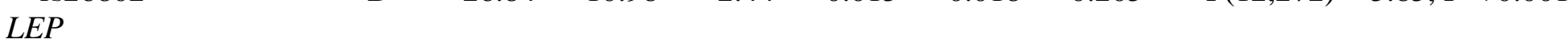 } \\
\hline rs $10244329^{a}$ & $\mathrm{R}$ & -21.01 & 25.39 & 0.83 & 0.409 & 0.012 & 0.213 & $\mathrm{~F}(14,271)=5.24, \mathrm{P}<0.001$ \\
\hline YRS*rs10244329 & & 3.76 & 1.78 & 2.11 & 0.036 & 0.013 & & \\
\hline
\end{tabular}




\begin{tabular}{|c|c|c|c|c|c|c|c|c|}
\hline $\begin{array}{c}\text { Sleep outcome / GENE } \\
\text { SNP / *interaction }\end{array}$ & Model & $\mathrm{b}$ & SE & $\mathrm{t}$ & $\mathrm{P}$ & $\Delta \mathrm{R}^{2}$ & $\mathrm{R}^{2}$ & Full models \\
\hline rs11760956 ${ }^{\mathrm{a}}$ & $\mathrm{A}$ & 41.20 & 17.75 & 2.32 & 0.021 & 0.000 & 0.208 & $\mathrm{~F}(14,271)=5.08, \mathrm{P}<0.001$ \\
\hline YRS*rs11760956 & & -3.22 & 1.22 & 2.63 & 0.009 & 0.020 & & \\
\hline $\mathrm{rs} 3828942^{\mathrm{a}}$ & $\mathrm{D}$ & -73.77 & 27.25 & 2.71 & 0.007 & 0.001 & 0.206 & $\mathrm{~F}(14,251)=4.64, \mathrm{P}<0.001$ \\
\hline VL*rs3828942 & & 26.33 & 9.41 & 2.80 & 0.006 & 0.025 & & \\
\hline \multicolumn{9}{|l|}{ PPARA } \\
\hline rs 135551 & A & -20.02 & 8.74 & 2.29 & 0.023 & 0.015 & 0.203 & $F(12,272)=5.78, P<0.001$ \\
\hline rs135547 & A & -20.17 & 8.51 & 2.37 & 0.018 & 0.016 & 0.208 & $\mathrm{~F}(12,272)=5.93, \mathrm{P}<0.001$ \\
\hline rs 4253655 & $\mathrm{D}$ & 118.13 & 34.81 & 3.39 & 0.001 & 0.030 & 0.232 & $\mathrm{~F}(14,271)=5.83, \mathrm{P}<0.001$ \\
\hline YRS*rs4253655 & & -4.74 & 2.17 & 2.18 & 0.030 & 0.014 & & \\
\hline rs $8138102^{\mathrm{a}}$ & A & 45.23 & 20.75 & 2.18 & 0.030 & 0.000 & 0.202 & $\mathrm{~F}(14,251)=4.53, \mathrm{P}<0.001$ \\
\hline VL*rs8138102 & & -19.06 & 7.37 & 2.59 & 0.010 & 0.021 & & \\
\hline rs4253776 & D & 84.04 & 29.25 & 2.87 & 0.004 & 0.001 & 0.209 & $\mathrm{~F}(14,252)=4.75, \mathrm{P}<0.001$ \\
\hline VL*rs4253776 & & -28.78 & 9.53 & 3.02 & 0.003 & 0.029 & & \\
\hline \multicolumn{9}{|l|}{$P P A R G$} \\
\hline rs12490265 & $\mathrm{D}$ & -55.24 & 28.03 & 1.97 & 0.050 & 0.007 & 0.213 & $\mathrm{~F}(14,252)=4.88, \mathrm{P}<0.001$ \\
\hline VL*rs $12490265^{\mathrm{c}}$ & & 27.71 & 9.45 & 2.93 & 0.004 & 0.027 & & \\
\hline rs796313 & $\mathrm{D}$ & -39.55 & 29.43 & 1.34 & 0.180 & 0.004 & 0.197 & $\mathrm{~F}(14,252)=4.41, \mathrm{P}<0.001$ \\
\hline VL*rs796313 & & 20.40 & 10.02 & 2.04 & 0.043 & 0.013 & & \\
\hline rs709151 & $\mathrm{D}$ & 98.88 & 44.06 & 2.24 & 0.026 & 0.000 & 0.208 & $\mathrm{~F}(14,271)=5.07, \mathrm{P}<0.001$ \\
\hline YRS*rs709151 ${ }^{\mathrm{d}}$ & & -8.66 & 3.32 & 2.60 & 0.010 & 0.020 & & \\
\hline
\end{tabular}

All models adjusted for genomic estimates of ancestry and self-reported race. In addition, WASO models adjusted for gender, the interaction of race and gender, CD4+ T-cell count, waist circumference, and use of opiate or antiemetic medication. TST models also adjusted for gender, waist circumference, smoking status, and use of neuroleptic or antiemetic medication. Analyses were conducted with square root-transformed WASO and CD4+ T-cell count values. Sample sizes for each analysis: $\mathrm{n}=272-273$ for WASO models, and $\mathrm{n}=285-286$ for TST models. A, additive model; $A D I P O Q$, adiponectin gene; D, dominant model; GHRL, ghrelin gene; $L E P$, leptin gene, PPARA, peroxisome proliferator-activated receptor alpha gene; PPARG, peroxisome proliferator-activated receptor gamma gene; $\mathrm{R}$, recessive model; $\mathrm{R}^{2}$, proportion of variance in sleep outcome explained by the full model; $\Delta \mathrm{R}^{2}$, proportion of variance in sleep outcome accounted for by genotype when adjusting for covariates; SE, standard error; SNP, single nucleotide polymorphism; t, t statistic; TST, total sleep time; VL, interaction between SNP and viral load; WASO, wake after sleep onset; YRS, interaction between SNP and years since HIV diagnosis.

${ }^{\text {a }}$ This SNP was not significantly associated with TST in unadjusted associations. 
${ }^{\mathrm{b}}$ Although the additive model was slightly stronger than the recessive model in unadjusted analyses $(\mathrm{P}=0.005$ versus 0.006 , respectively) and was therefore reported in Table 2, only the recessive model was significant in adjusted analyses.

${ }^{\mathrm{c}}$ The genotype also had a significant interaction with years since HIV diagnosis, but since the viral load model was stronger, it is the one reported.

${ }^{\mathrm{d}}$ The genotype also had a significant interaction with viral load, but since the model with years since diagnosis was stronger, it is the one reported. 
Table 5. Spearman correlations between plasma markers of energy homeostasis and sleep parameters

\begin{tabular}{lrlcc}
\hline Plasma markers & $\mathrm{N}$ & mean $(S D)$ & $\begin{array}{c}\text { WASO } \\
\text { rho }\end{array}$ & $\begin{array}{c}\text { TST } \\
\text { rho }\end{array}$ \\
\hline Adiponectin (ng/mL) & 287 & $14.3(9.2)$ & & \\
$\quad$ Male & 192 & $12.4(8.0)$ & .067 & -.006 \\
$\quad$ Female & 73 & $18.3(9.5)$ & -.045 & .008 \\
$\quad$ Transgender & 22 & $17.1(12.7)$ & .095 & -.073 \\
Ghrelin (ng/mL) & 280 & $1.39(1.07)$ & -.023 & .046 \\
Leptin, (ng/mL) & 287 & $10.3(13.2)$ & & \\
$\quad$ Male & 192 & $5.7(6.5)$ & .059 & -.099 \\
$\quad$ Female & 73 & $20.8(17.9)$ & .024 & .078 \\
$\quad$ Transgender & 22 & $15.4(16.8)$ & .135 & .082 \\
Insulin, pg/mL & 286 & $83.2(55.7)$ & .065 & -.045 \\
Glucose, mg/dL & 194 & $95.7(24.7)$ & $.169 *$ & $-.165^{*}$ \\
C-peptide, pg/mL & 287 & $161(161)$ & .013 & .067 \\
\hline mg/mL, milligrams per milliliter; ng/mL, nanograms per milliliter; pg/mL, picograms per \\
milliliter; SD, standard deviation; TST, total sleep time; WASO, wake after sleep onset. \\
* $\quad \mathrm{P} \quad<$
\end{tabular}


Table 6. Significant adjusted associations between plasma markers of energy homeostasis and sleep parameters

\begin{tabular}{|c|c|c|c|c|c|c|c|}
\hline $\begin{array}{l}\text { Plasma biomarker } \\
\text { *interaction }\end{array}$ & $\mathrm{b}$ & $\mathrm{SE}$ & $\mathrm{t}$ & $\mathrm{P}$ & $\Delta \mathrm{R}^{2}$ & $\mathrm{R}^{2}$ & Full models \\
\hline \multicolumn{8}{|l|}{ WASO } \\
\hline Adiponectin $^{\mathrm{a}}$ & -0.012 & 0.006 & 1.98 & 0.049 & 0.000 & 0.232 & $\mathrm{~F}(18,246)=4.13, \mathrm{P}<0.001$ \\
\hline VL*Adiponectin & 0.004 & 0.002 & 2.08 & 0.038 & 0.014 & & \\
\hline \multicolumn{8}{|l|}{ TST } \\
\hline Ghrelin ${ }^{b}$ & -71.48 & 39.57 & 1.81 & 0.072 & 0.003 & 0.200 & $\mathrm{~F}(14,243)=4.33, \mathrm{P}<0.001$ \\
\hline VL*Ghrelin & 31.93 & 13.14 & 2.43 & 0.016 & 0.019 & & \\
\hline Leptin $^{\mathrm{b}}$ & 70.08 & 29.06 & 2.41 & 0.017 & 0.000 & 0.208 & $\mathrm{~F}(14,250)=4.69, \mathrm{P}<0.001$ \\
\hline VL*Leptin & -27.04 & 9.21 & 2.94 & 0.004 & 0.027 & & \\
\hline Glucose $^{c^{1}}$ & -30.46 & 7.93 & 3.84 & $<0.001$ & 0.034 & 0.263 & $\mathrm{~F}(13,173)=4.74, \mathrm{P}<0.001$ \\
\hline VL*Glucose ${ }^{c}$ & 8.22 & 2.79 & 2.95 & 0.004 & 0.037 & & \\
\hline
\end{tabular}

All models adjusted for genomic estimates of ancestry and self-reported race. In addition, WASO models adjusted for gender, the interaction of race and gender, CD4+ T-cell count, waist circumference, and use of opiate or antiemetic medication. TST models adjusted for gender, waist circumference, smoking status, and use of neuroleptic or antiemetic medication. b, regression coefficient; $\mathrm{P}$, P-value; SE, standard error; $\mathrm{t}$, $\mathrm{t}$ statistic; TST, total sleep time; VL, viral load; WASO, wake after sleep onset (square root-transformed).

${ }^{\text {a }}$ Square root-transformed adiponectin values were used in this analysis.

${ }^{\mathrm{b}}$ Log-transformed ghrelin and leptin values were used in this analysis.

${ }^{\mathrm{c}}$ Inverse-transformed glucose values multiplied by 1000 were used in the analysis, but the signs of $b$ have been corrected to reflect the direction of the relationship between raw glucose values and TST. $\mathrm{N}=187$ due to missing glucose values. 
Figure Captions

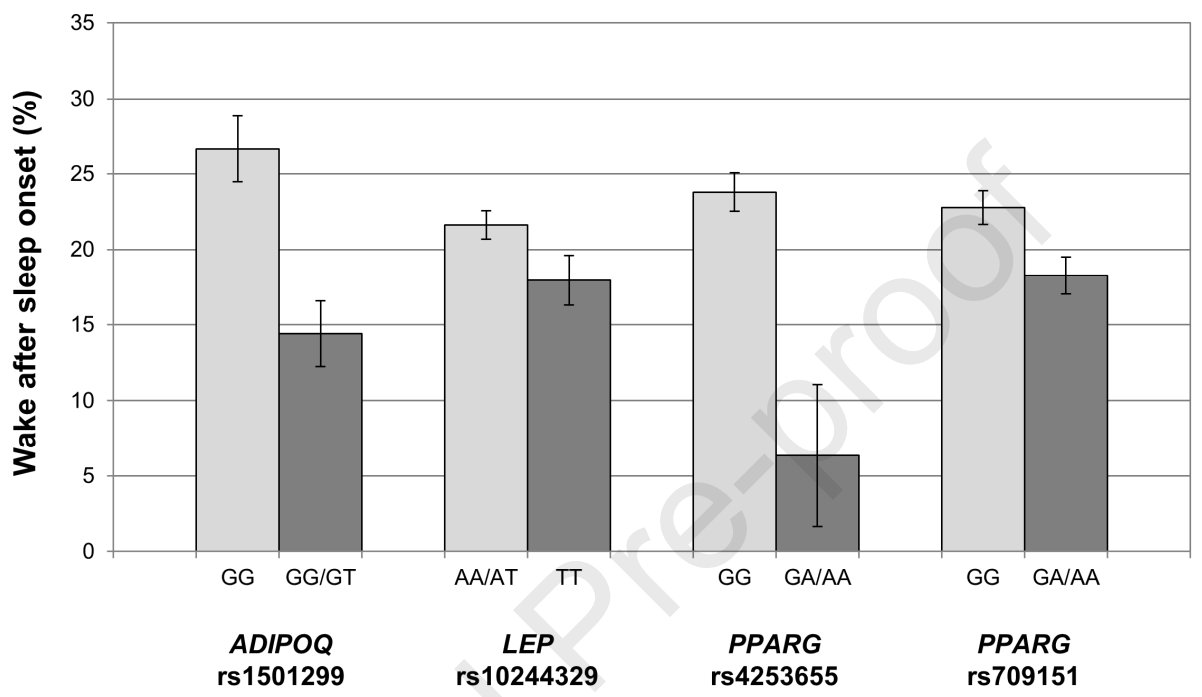

Figure 1. Wake after sleep onset for a selection of 4 of the 9 associated genotypes in adjusted analyses. Carriers of the minor allele for $A D I P O Q$ rs 1501299 had significantly less wake after sleep onset than carriers of two doses of the major allele. Carriers of two doses of the minor allele for $L E P$ rs10244329 had less wake after sleep onset than carriers of the major allele. Carriers of the minor allele for PPARA rs4253655 had less wake after sleep onset compared to carriers of two doses of the major allele, and carriers of the minor allele for PPARG rs709151 also had less wake after sleep onset than carriers of two doses of the major allele. All $\mathrm{P}$ values $<0.05$. 


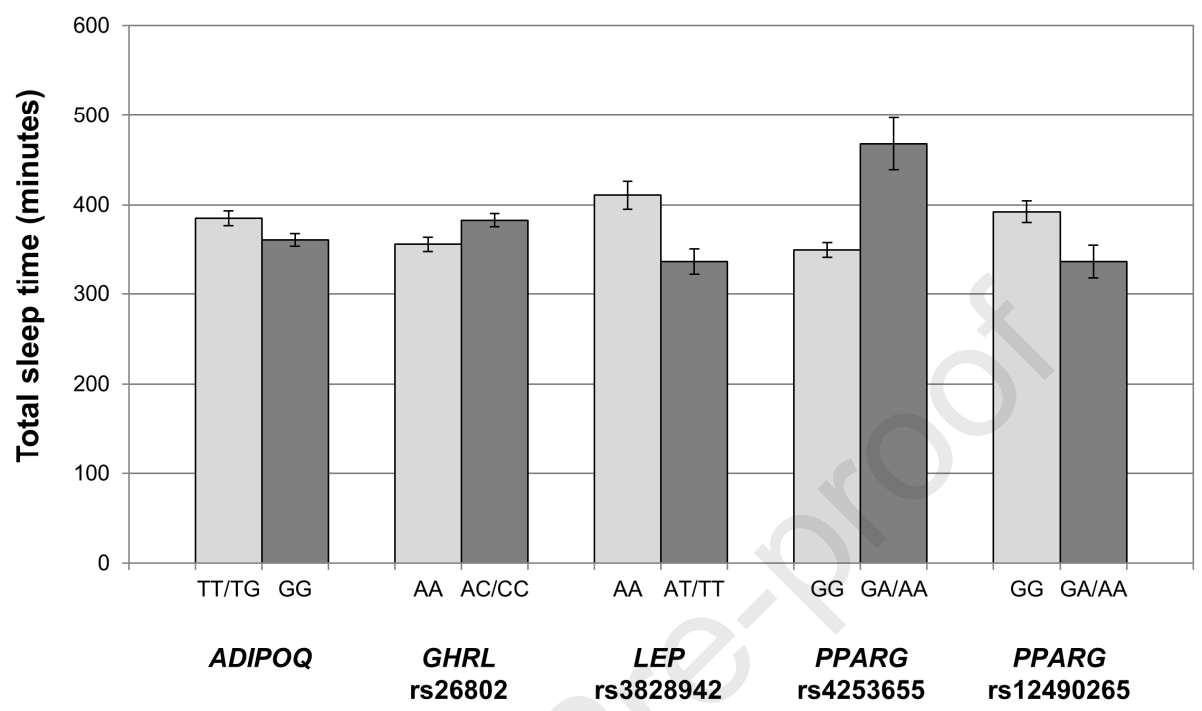

Figure 2. Total sleep time for a selection of 5 of the 14 associated genotypes in adjusted analyses. Compared to carries of the major allele for ADIPOQ rs2241766, carriers of two doses of the minor allele had less total sleep per night. Carriers of the minor allele for GHRL rs26802 and PPARA rs4253655 had more total sleep time than carriers of two doses of the major allele, whereas carriers of the minor allele for LEP rs3828942 and PPARG rs12490265 had less total sleep time than carriers of two doses of the major allele. All $\mathrm{P}$ values $<0.05$. 


\section{Highlights}

- Sleep disruption and duration are not independent sleep parameters.

- 17 SNPs from five candidate genes involved in energy homeostasis (ADIPOQ, GHRL, LEP, PPARA, and PPARG) were associated with sleep disruption and/or duration in adults with HIV/AIDS.

- Higher plasma adiponectin was associated with less WASO; higher ghrelin and glucose levels were associated with shorter TST; and higher leptin was associated with longer TST.

- Poor sleep is prevalent in HIV-positive adults, and adjusting for HIV clinical indicators is important when assessing genetic associations with poor sleep.

- Results provide direction for developing precision pharmacologic therapy to improve sleep. 
CRediT author statement

Bradley E. Aouizerat: Conceptualization, Methodology, Investigation, Formal analysis, Writing Original Draft; Eeeseung Byun: Investigation, Writing - Review \& Editing; Clive R. Pullinger: Investigation, Writing - Review \& Editing; Caryl Gay: Investigation, Formal analysis, Project administration, Visualization, Writing - Review \& Editing; Anners Lerdal: Investigation, Writing - Review \& Editing; Kathryn A. Lee: Conceptualization, Methodology , Investigation, Formal analysis, Supervision, Writing - Review \& Editing, Funding acquisition 